\title{
New progress in development of ferroelectric and piezoelectric nanoceramics
}

\author{
Xiao-Hui WANG ${ }^{a,}{ }^{*}$, I-Wei $\mathrm{CHEN}^{b}$, Xiang-Yun DENG ${ }^{a}$, Yu-Di WANG ${ }^{b}$, Long-Tu LI ${ }^{a}$ \\ ${ }^{a}$ State Key Laboratory of New Ceramics and Fine Processing, School of Materials Science and Engineering, \\ Tsinghua University, Beijing 100084, China \\ ${ }^{b}$ Department of Materials Science and Engineering, University of Pennsylvania, Philadelphia, \\ PA 19104-6272, USA
}

Received: November 06, 2014; Accepted: November 27, 2014

(c) The Author(s) 2015. This article is published with open access at Springerlink.com

\begin{abstract}
There has been great progress in the last decade in the synthesis of nanopowders with highly controlled size and size distribution. Meanwhile, the development of an unconventional pressureless two-step sintering strategy enabling densification without grain growth provides a novel technology suitable for commercial production of nanograin ceramics. The particular interest concerning bulk dense nanograin ceramics is the manifestation of ferroelectricity, which remains a fundamental issue to be understood and exploited. Combining the best powder synthesis and optimized two-step sintering, high-density barium titanate (BT) and related nanograin ceramics have been fabricated to allow for a detailed determination of the size effect on nanometer-scale ferroelectricity and piezoelectricity of fundamental and industrial interest. These include dense ceramics of undoped BT with an average grain size down to $5 \mathrm{~nm}$, and of $(1-x) \mathrm{BiScO}_{3}-x \mathrm{PbTiO}_{3}$ (BSPT) solid solutions with an average grain size down to $10 \mathrm{~nm}$. Here we review the fabrication methods of high-density BT and BSPT nanoceramics and the major findings of the size effect on their microstructure, phase transition and electrical properties. Robust ferroelectricity is demonstrated for the first time in $5 \mathrm{~nm}$ BT nanoceramics, while strong local piezoelectricity is present in $10 \mathrm{~nm}$ BSPT nanoceramics.
\end{abstract}

Keywords: nanoceramic; ferroelectric; piezoelectric; barium titanate; size effect

\section{Introduction}

Barium titanate $\left(\mathrm{BaTiO}_{3}, \mathrm{BT}\right)$ of the perovskite $\mathrm{ABO}_{3}$ type has played an important part in the modern ceramic industry because of its advantageous ferroelectric, piezoelectric and dielectric properties, finding applications in multilayer ceramic capacitors, printed circuit boards, random access memory, positive temperature coefficient of resistance thermistors,

\footnotetext{
* Corresponding author.

E-mail: wxh@mail.tsinghua.edu.cn
}

piezoelectric sensors, and actuators [1-4]. Since the 1970 s, polycrystalline multilayer ceramic capacitors (MLCCs) made of ferroelectric BT have been deployed for ever-expanding applications, aided in recent years by incorporating nickel $(\mathrm{Ni}$, a so-called base metal) electrode made feasible by low temperature firing. Driven by the demand of ever smaller sizes, higher performance and lower component costs in electronic industry, the evolution of MLCCs with base metal inter-electrodes (BME) and thinner dielectric layers is continuing [5-7]. MLCCs capable of $10^{-13} \mathrm{~F}$ to $10^{-4} \mathrm{~F}$ are used in products from 
computers to automobiles. Currently, $10^{13}$ new pieces of MLCCs enter the market every year. As their layer thickness decreases below $1 \mu \mathrm{m}$ and the attendant ceramic grain size (GS) shrinks below $100 \mathrm{~nm}$, MLCC represents the most significant nanograin ceramics in use today. This prospect is expected to continue in the next decade.

The driving force toward nanograin MLCC ceramics has come from not only component miniaturization but also performance. However, it is well known that once the grain size is decreased below $1 \mu \mathrm{m}$, a rapid decrease of dielectric constant $(K)$ is common. This drop may pose a limitation to the miniaturization of MLCCs since miniaturization of MLCCs usually goes hand in hand with grain size reduction. Typically, the dielectric layer has to comprise of at least 5-7 grains across the thickness, for reasons of layer flatness, high reliability and uniform properties. It follows that in a layer of $0.5-0.7 \mu \mathrm{m}$ thick, the grain size must be maintained below $100 \mathrm{~nm}$. Consequently, it is of great practical interest to prepare dense nanograin BT and other related ceramics and to investigate their dielectric, ferroelectric and piezoelectric characteristics: the findings should provide important directions for the design of next generation MLCCs.

Grain size has a profound influence on the crystal structure and properties of BT ceramics [8-10]. Coarse-grain BT ceramics undergo several phase transitions as a function of temperature. Starting from a low temperature at about $-75^{\circ} \mathrm{C}$, BT begins to transform, from a rhombohedral (R) to an orthorhombic $(\mathrm{O})$ structure, then to a tetragonal $(\mathrm{T})$ phase at about $5{ }^{\circ} \mathrm{C}$, and finally to a cubic (C) phase at around $130{ }^{\circ} \mathrm{C}$ [11]. The $\mathrm{C} \rightarrow \mathrm{T}$ phase transition is a ferroelectric transition; therefore, it also drives the formation of polydomain subgrains or domains, which minimize electrostatic and elastic energies in the polar, non-isometric state. It has been generally speculated that there is a critical grain size below which ferroelectricity-embodied by the ferroelectric $\mathrm{T}$ to $\mathrm{C}$ distortion-is lost. Structural studies on BT ceramics by Frey and Payne [9], however, indicated the retention of a long-range cooperative driving force for the distortion at a grain size well below $100 \mathrm{~nm}$. Other estimates have placed the critical size in the range of $10-30 \mathrm{~nm}$ for BT ceramics [12]. On the other hand, recent studies [12-14] on dielectric properties have shown that there is a "dilution effect", caused by the presence of a lower permittivity (nonferroelectric) dead layer along the grain boundary, which can considerably lower the permittivity in submicron and nanocrystalline BT ceramics and thin films. The dead layer is not necessarily a second phase; it could be accounted by a crystalline BT layer with a more disordered/defective structure or a ferroelectric layer that is non-switchable because of polarization clamping by surface or grain boundary. The latter could be due to mechanical origin or electrical origin: in this scenario, ferroelectric perovskite has a correlation length of about $1-3 \mathrm{~nm}$, which is the scale within which the polarization is clamped by the dielectric boundary, thus providing an estimate of the dead layer thickness. Whether this picture is entirely correct or not is currently not known. Experimentally, though, Buscaglia et al. [15] already reported a dense (spark plasma sintered) $30 \mathrm{~nm}$ (GS) BT ceramic which has a high dielectric constant but a frozen macroscopic polarization suggesting a strong clamping but little dilution effect.

Obviously, whether nanograin BT can provide an elevated $K$ itself is an important practical issue which has been repeatedly questioned in the literature. In the coarse-grain regime, $K$ has a well-known maximum at $\mathrm{GS} \approx 1 \mu \mathrm{m}$ [9], below which $K$ decreases. In our 2006 work on a dense BT ceramic fabricated by two-step sintering method, we found microscopy evidence of ferroelectric polydomain state in samples with an average grain size as small as $8 \mathrm{~nm}$ [16]. We also found it to display a robust $K$-temperature $(T)$ performance, with a very low dielectric loss and a clear evidence of multiple dielectric/ferroelectric transitions. This implies that a ceramic capacitor with a layer thickness of 40-50 nm (containing 5-7 grains of $8 \mathrm{~nm}$ sized) is still viable. To predict the critical grain size, a phenomenological thermodynamic theory with an additional consideration of stress effects caused by surface bond contraction was proposed by Sun et al. [17]. It predicts changing trends in phase transitions and the critical grain size for the disappearance of the ferroelectric phases, including two opposite relationships between the grain size and (two kinds of) stresses. The size that leads to the disappearance of ferroelectric phases at room temperature is found at about $5.2 \mathrm{~nm}$. When the grain is less than $2.5 \mathrm{~nm}$, the ferroelectric phases are fully absent over the entire temperature region. Most recently, to determine whether it is feasible to fabricate sub- $5 \mathrm{~nm}$ ceramics, we fabricated ultrafine BT nanocrystalline powders of 3-5 $\mathrm{nm}$ using a one-step solvothermal method [18], 
and then obtained, by two-step sintering, dense BT ceramics with a grain size of $5 \mathrm{~nm}$, which set the record for the finest dense bulk nanograin material. This is reassuring for the MLCC industry and augurs well for the status-quo MLCC fabrication method (with tape-casting of green layers, screen printing of electrodes and co-firing of $\mathrm{BaTiO}_{3} /$ electrode stacks of hundreds of layers): with incremental changes and advances, they may continue for the foreseeable future.

On the piezoelectric side, $(1-x) \mathrm{BiScO}_{3}-x \mathrm{PbTiO}_{3}$ (BSPT) is a solid solution which was first investigated by Eitel et al. [19] in 2001 as a member of a new family of high-temperature piezoelectric ceramics. They investigated a series of complex perovskites with the general formula $\mathrm{Bi}\left(\mathrm{Me}^{3+}\right) \mathrm{O}_{3}-\mathrm{PbTiO}_{3}\left(\mathrm{Me}^{3+}=\mathrm{Sc}^{3+}\right.$, $\mathrm{Fe}^{3+}, \mathrm{In}^{3+}, \mathrm{Yb}^{3+}$, etc.) that have a large deviation from unity for the tolerance factor $t$ of Goldschmidt [20]. Among these solid solutions, BSPT is the only one that has a tolerance factor $(t=0.907)$ less than that of $\mathrm{Pb}(\mathrm{Zr}, \mathrm{Ti}) \mathrm{O}_{3}$ (PZT, $\left.t=0.96\right)$ and still maintains a stable perovskite structure under atmospheric conditions. It exhibits a high $T_{\mathrm{C}}$ of $450{ }^{\circ} \mathrm{C}$ at compositions near the morphotropic phase boundary (MPB) and has outstanding piezoelectric properties (electromechanical coupling factor $K_{\mathrm{p}}=0.57$, piezoelectric constant $d_{33}=$ $450 \mathrm{pC} / \mathrm{N})$. Extensive studies have since been carried out on BSPT ceramics [19,21-31], single crystals [32-36] and thin films [37-43], confirming their high Curie temperature, excellent ferroelectric/piezoelectric properties and robust thermal stability. For example, in our previous study on BSPT ceramics [25], we obtained the best piezoelectric properties at $x=0.635$ (near the MPB): $d_{33}=700 \mathrm{pC} / \mathrm{N}$ and $K_{\mathrm{p}}=0.632$, with a Curie temperature of $446^{\circ} \mathrm{C}$, all higher than those of PZT. Because of these excellent properties, BSPT is a promising candidate material for high-temperature sensors and actuators. On the other hand, investigations of the grain size effect on piezoelectric ceramics [44] are still few and there is no consistent conclusion on this subject for nanograin BSPT ceramics. Using two-step sintering, we have fabricated dense BSPT ceramics with average grain size from $1 \mu \mathrm{m}$ down to about $10 \mathrm{~nm}$. These ceramics thus provide an opportunity for studying the grain size effect on BSPT ceramics.

In the following, we will provide an overview of the methods for fabricating dense BT and BSPT nanograin ceramics and the investigation of the grain size effect on their microstructures, phase transition and dielectric, piezoelectric and ferroelectric properties. The existence of the ferroelectric phase in these ceramics at room temperature will be probed by the hysteresis loops of polarization reversal, as is the corresponding local ferroelectric switching hysteresis being recorded by piezoresponse force microscopy. These results provide the first experimental evidence for ferroelectricity and piezoelectricity in bulk dense below-10 nm BT and BSPT ceramics with their respective high Curie temperatures.

\section{Preparation of nanograin ceramics by two-step sintering}

\section{2. $1 \mathrm{BaTiO}_{3}$}

Nanopowders of BT with well-defined crystallinity, high purity and a narrow particle size distribution are generally required for manufacturing nanograin ceramics. Low crystallinity is itself a problem emanating from the size effect, but hydroxyl ion incorporation from the air is another reason for low crystallinity. The development of new methods to synthesize monodispersed BT nanocrystals will facilitate the studies of the size effect. Hydrothermal synthesis of ceramic powders with well-controlled parameters (concentration, $\mathrm{pH}$ and temperature) has been widely reported, especially for low-temperature preparation of relatively single-phase products $[45,46]$. This method has been used to prepare highly dispersed BT powders with a particle size smaller than several tens of nanometers. However, aqueous hydrothermal systems mostly produce cubic BT phase powders; to obtain the tetragonal phase capable of ferroelectricity annealing at high temperature is necessary, but with it crystallite size growth and powder aggregation are inevitable. Thus, non-aqueous reaction approaches may have considerable advantages in controlling crystallization and particle growth. Monodispersed BT nanocrystals with the tetragonal structure have been synthesized using a one-step solvothermal method in our laboratory [18]. They have an average size of about 3-5 nm with a narrow distribution, with a high-resolution transmission electron microscopy (HRTEM) image illustrated in the inset of Fig. 1(a), which indicates well-crystallized nanoparticles. A lattice tetragonality ( $c / a$ ratio) of 1.0069 can also be discerned from the TEM micrograph in Fig. 1(a) for $5 \mathrm{~nm}$ particles. The particle size distribution with an 


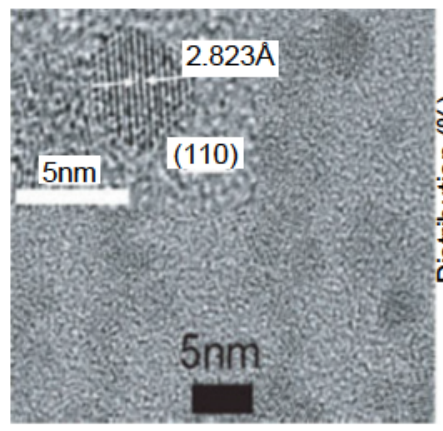

(a)

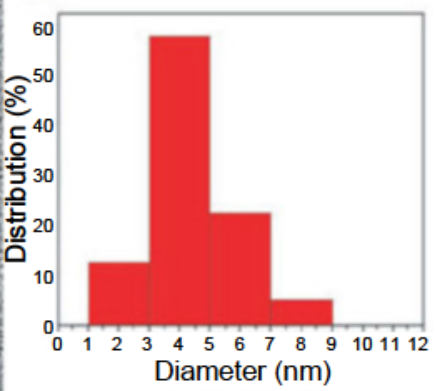

(b)
Fig. 1 (a) TEM image and (b) size distribution of $5 \mathrm{~nm}$ BT nanoparticles.

average size of $5 \mathrm{~nm}$ is shown in Fig. 1(b).

Two-step sintering (TSS) was invented to allow fabricating dense nanograin ceramics $\mathrm{Y}_{2} \mathrm{O}_{3}$ (a highly refractory oxide with a melting point of $2600{ }^{\circ} \mathrm{C}$ ) without pressure [47]. It has since been proved to be a highly efficient method to prepare other kinds of dense nanograin bulk ceramics, including both oxides and nonoxides [48-53]. In this method, the ceramic is first fired at a higher temperature $T_{1}$ to reach a critical density (typically $75 \%$ so that the average pore is relatively small compared to the grains, thus acquiring capillary driving force to spontaneously sinter and not to coarsen). Subsequently, the temperature is lowered to $T_{2}$ to allow further densification all the way to full density. The remarkable feature of this procedure is that there is no grain growth during the second step densification apparently because the four-grain junctions are "frozen" thus resisting grain boundary migration even though grain boundary diffusion still proceeds. This is rather unique and completely unlike the case in normal sintering in which final stage densification is always accompanied by rapid grain growth. This method was initially applied to $\mathrm{Y}_{2} \mathrm{O}_{3}$, which we sintered to full density at $1000{ }^{\circ} \mathrm{C}$ without doping, or at $800{ }^{\circ} \mathrm{C}$ with 1 cation $\% \mathrm{Mg}$ doping [47,54]. It was also successfully used to sinter undoped BT ceramics (fully dense at as low as $750{ }^{\circ} \mathrm{C}$ ) [51]. The dramatic contrast of the microstructure development of BT ceramics in normal sintering and in TSS can be seen in Fig. 2, where several grain size-density trajectories are depicted. It is clear that grain growth during the secondstep sintering $\left(T_{2}<T_{1}\right)$ was completely suppressed.

Dense (99.6\% of theoretical density) BT ceramics around $8 \mathrm{~nm}$ were also obtained by us using TSS $[16,55]$. Figure 3(a) shows its microstructure under TEM. The grain size is very uniform with a narrow distribution. The inset of Fig. 3(a) is a high-resolution

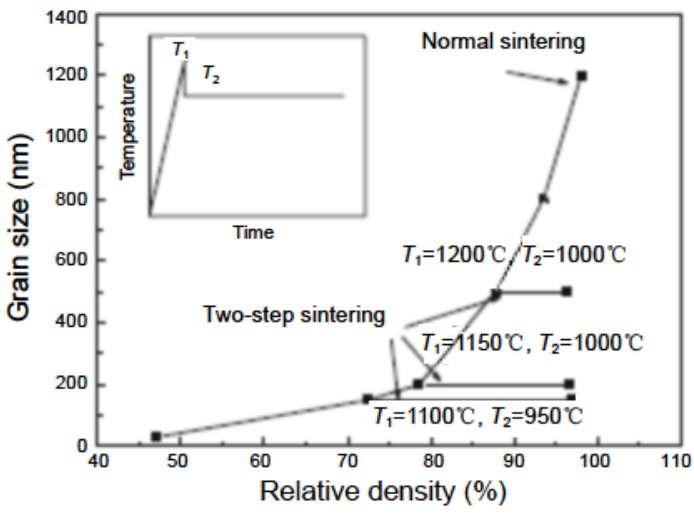

Fig. 2 Grain size versus density for BT ceramics sintered by two-step sintering and by normal sintering.

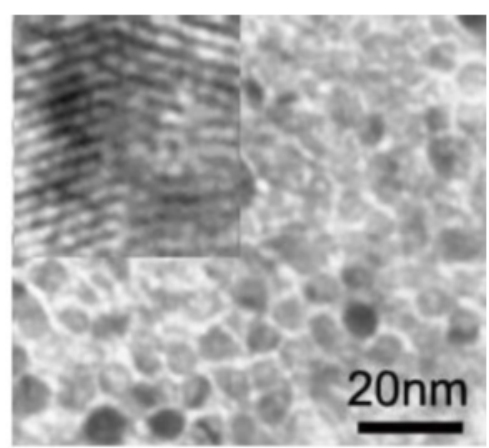

(a) $8 \mathrm{~nm}$ TEM (inset HRTEM)

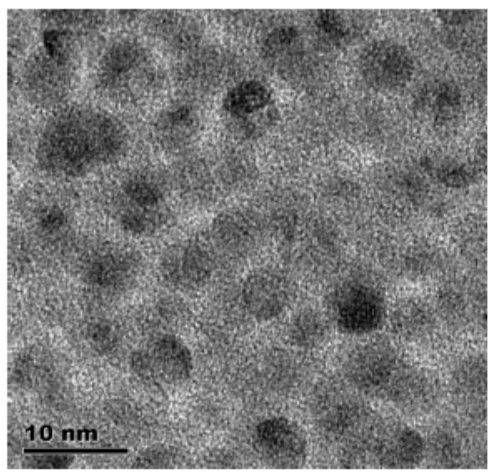

(b) $5 \mathrm{~nm}$ TEM

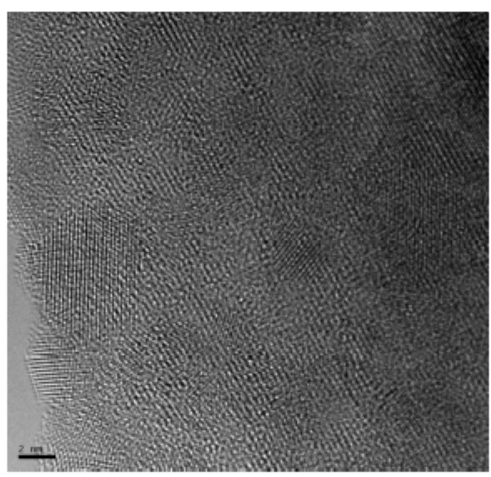

(c) $5 \mathrm{~nm}$ AC-HRTEM

Fig. 3 TEM and HRTEM images of BT ceramics with grain sizes of $8 \mathrm{~nm}$ and $5 \mathrm{~nm}$. 
image of the $8 \mathrm{~nm}$ sample, which is free of impurity phase and the grain boundary is about $0.4 \mathrm{~nm}$ thick. This grain boundary thickness is roughly equal to the lattice constant of BT and is much smaller than the data for BT nanoceramics in the literature. Recently, using 3-5 nm nanopowders of BT (by solvothermal synthesis) mentioned above, aided by cold isotropic pressing (CIP) with an ultrahigh pressure (6 GPa), we obtained dense BT nanoceramic with a grain size of $5 \mathrm{~nm}$ again by TSS (Figs. 3(b) and 3(c), the latter is an aberration-corrected HRTEM (AC-HRTEM) image) [56], which is the finest BT ceramic ever obtained.

Employing the two-step sintering strategy without applying a high pressure during CIP, a series of highdensity bulk BT ceramic samples with grain size ranging from micrometer to $30 \mathrm{~nm}$ scale have also been prepared [56-58]. Table 1 lists some of the successful two-step sintering experiments $\left(\mathrm{BaTiO}_{3}-1-\right.$ $\mathrm{BaTiO}_{3}-18$ ) using $10 \mathrm{~nm}, 30 \mathrm{~nm}$ and $100 \mathrm{~nm}$ BT powders. These experiments all achieved high density $(\geqslant 96 \%)$ without grain growth in the second step. Larger grained samples were also obtained by increasing $T_{2}$ to allow some grain growth $\left(\mathrm{BaTiO}_{3}-19\right.$ : $\mathrm{GS}=4.32 \mu \mathrm{m}$ and $\mathrm{BaTiO}_{3}-20: \mathrm{GS}=8.61 \mu \mathrm{m}$, in Table 1). Together, these ceramics provided a set of samples for the systematic investigation of the size effect on tetragonal distortion, phase transition, Curie temperature and dielectric properties to be described later.

\section{$2.2(1-x) \mathrm{BiScO}_{3}-x \mathrm{PbTiO}_{3}$}

A citrate sol-gel method was utilized to synthesize BSPT nanopowders with a near MPB composition $(x=$
$0.635-0.64)$ and grain size of $6-10 \mathrm{~nm}[24,25]$. Optimum parameters of two-step sintering were investigated using the data summarized in Table 2 and Fig. 4 [24]. The wedge shape region of the $T_{2}$ window for successful sintering in Fig. 4 resembles that for $\mathrm{Y}_{2} \mathrm{O}_{3}$ and $\mathrm{BaTiO}_{3}$ (see our previous publications [47,51]), suggesting similar thermodynamics and kinetics underlying two-step sintering in different ceramics. Using these conditions, highly dense MPB BSPT ceramics with homogeneous fine grains as small as $200 \mathrm{~nm}$ can be obtained at $800{ }^{\circ} \mathrm{C}$ without sintering aid $[24,25]$.

Ceramics of much finer grain size can also be obtained from nanopowders by introducing additional

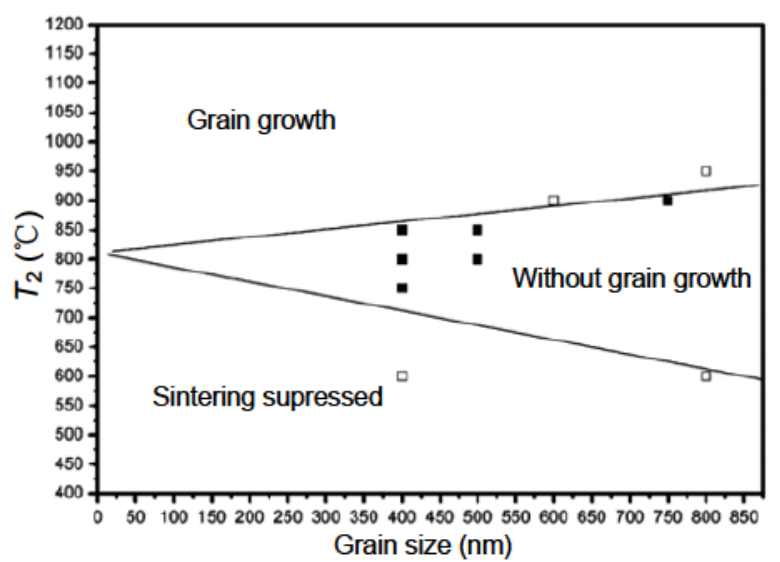

Fig. 4 Kinetic window for reaching full density without grain growth for BSPT ceramics. Solid symbols present successful sintering conditions, and open symbols indicate those that cannot reach high density (below the lower boundary) or cause uncontrolled grain growth (above the upper boundary).

Table 1 Two-step sintering results of BT ceramics (initial powder sizes of $10 \mathrm{~nm}, 30 \mathrm{~nm}$ and $100 \mathrm{~nm}$ )

\begin{tabular}{|c|c|c|c|c|c|c|c|c|c|}
\hline \multirow{2}{*}{ Sample } & \multirow{2}{*}{$\rho_{0}(\%)$} & \multicolumn{4}{|c|}{ After 1st-step sintering } & \multicolumn{4}{|c|}{ After 2nd-step sintering } \\
\hline & & $T_{1}\left({ }^{\circ} \mathrm{C}\right)$ & $t_{1}(\mathrm{~h})$ & $\rho_{1}(\%)$ & $\mathrm{GS}_{1}(\mathrm{~nm})$ & $T_{2}\left({ }^{\circ} \mathrm{C}\right)$ & $t_{2}(\mathrm{~h})$ & $\rho_{2}(\%)$ & $\mathrm{GS}_{2}(\mathrm{~nm})$ \\
\hline $\mathrm{BaTiO}_{3}-1^{*}$ & 61 & 950 & 0 & 86 & 33 & 900 & 2 & 98.0 & 35 \\
\hline $\mathrm{BaTiO}_{3}-2^{*}$ & 46 & 980 & 0 & 78 & 68 & 900 & 4 & 97.0 & 70 \\
\hline $\mathrm{BaTiO}_{3}-3$ & 46 & 1100 & 0 & 73 & 148 & 900 & 20 & 96.2 & 150 \\
\hline $\mathrm{BaTiO}_{3}-4 *$ & 46 & 1100 & 0 & 73 & 148 & 950 & 20 & 97.1 & 150 \\
\hline $\mathrm{BaTiO}_{3}-5^{* *}$ & 46 & 1150 & 0 & 78 & 200 & 900 & 20 & 96.3 & 200 \\
\hline $\mathrm{BaTiO}_{3}-6 *$ & 46 & 1150 & 0 & 78 & 200 & 1000 & 20 & 97.2 & 200 \\
\hline $\mathrm{BaTiO}_{3}-7^{* *}$ & 46 & 1180 & 0 & 83 & 296 & 950 & 20 & 97.0 & 300 \\
\hline $\mathrm{BaTiO}_{3}-8 *$ & 46 & 1180 & 0 & 83 & 296 & 1000 & 20 & 97.2 & 300 \\
\hline $\mathrm{BaTiO}_{3}-9^{* *}$ & 46 & 1200 & 0 & 87 & 495 & 850 & 20 & 96.0 & 500 \\
\hline $\mathrm{BaTiO}_{3}-10^{* *}$ & 46 & 1200 & 0 & 87 & 595 & 900 & 20 & 96.3 & 500 \\
\hline $\mathrm{BaTiO}_{3}-11^{* *}$ & 46 & 1200 & 0 & 87 & 495 & 1000 & 10 & 97.2 & 500 \\
\hline $\mathrm{BaTiO}_{3}-12^{* *}$ & 46 & 1200 & 0 & 87 & 495 & 1100 & 10 & 97.0 & 500 \\
\hline $\mathrm{BaTiO}_{3}-13^{* *}$ & 46 & 1230 & 0 & 90 & 795 & 850 & 20 & 97.5 & 800 \\
\hline $\mathrm{BaTiO}_{3}-14$ & 46 & 1230 & 0 & 90 & 795 & 1000 & 20 & 98.0 & 800 \\
\hline $\mathrm{BaTiO}_{3}-15^{* * *}$ & 48 & 1310 & 0 & 88 & 990 & 800 & 24 & 96.4 & 990 \\
\hline $\mathrm{BaTiO}_{3}-16$ & 48 & 1310 & 0 & 88 & 990 & 850 & 24 & 96.4 & 1020 \\
\hline $\mathrm{BaTiO}_{3}-17^{* * *}$ & 48 & 1340 & 0 & 90 & 1950 & 900 & 24 & 98.0 & 1970 \\
\hline $\mathrm{BaTiO}_{3}-18$ & 48 & 1340 & 0 & 90 & 1950 & 950 & 24 & 97.4 & 2210 \\
\hline $\mathrm{BaTiO}_{3}-19 * *$ & 48 & 1340 & 0 & 90 & 1950 & 1050 & 24 & 96.8 & 4320 \\
\hline $\mathrm{BaTiO}_{3}-20^{* * *}$ & 48 & 1340 & 0 & 90 & 1950 & 1100 & 24 & 96.5 & 8610 \\
\hline
\end{tabular}

Initial powder size of $10 \mathrm{~nm}$; "initial powder size of $30 \mathrm{~nm} ;{ }^{*}$ initial powder size of $100 \mathrm{~nm}$. 
Table 2 Parameters of two-step sintering for BSPT ceramics

\begin{tabular}{|c|c|c|c|c|c|}
\hline \multirow{2}{*}{ Sample } & \multicolumn{2}{|c|}{ Sintering method } & \multirow{2}{*}{$t(\mathrm{~h})$} & \multirow{2}{*}{$\begin{array}{c}\text { Relative } \\
\text { density (\%) }\end{array}$} & \multirow{2}{*}{ GS (nm) } \\
\hline & $T_{1}\left({ }^{\circ} \mathrm{C}\right)$ & $T_{2}\left({ }^{\circ} \mathrm{C}\right)$ & & & \\
\hline $\mathrm{A}$ & 930 & \multirow{2}{*}{800} & 8 & 71.8 & 350 \\
\hline $\mathrm{B}$ & 960 & & 8 & 89.0 & 390 \\
\hline $\mathrm{C}_{1}$ & \multirow{4}{*}{1000} & 750 & 8 & 96.1 & 400 \\
\hline $\mathrm{C}_{2}$ & & 800 & 8 & 98.8 & 400 \\
\hline $\mathrm{C}_{3}$ & & 850 & 8 & 95.8 & 400 \\
\hline $\mathrm{C}_{4}$ & & 900 & 8 & 98.0 & 600 \\
\hline $\mathrm{D}$ & 1020 & 800 & 8 & 97.9 & 470 \\
\hline$\overline{E_{1}}$ & \multirow{4}{*}{1050} & 800 & 8 & 98.1 & 497 \\
\hline $\mathrm{E}_{2}$ & & 850 & 8 & 98.5 & 497 \\
\hline $\mathrm{E}_{3}$ & & 900 & 8 & 97.4 & 750 \\
\hline $\mathrm{E}_{4}$ & & 950 & 8 & 95.5 & 795 \\
\hline
\end{tabular}

practice of high-pressure consolidation during forming or spark plasma sintering (SPS). Due to their extremely large specific surface area, BSPT nanopowders are rather sensitive to sintering temperature and holding time, and volatile additives such as $\mathrm{Pb}$ and $\mathrm{Bi}$ cannot be used since they tend to cause rapid grain growth. BSPT ceramics of $80 \mathrm{~nm}$ grain size were already obtained by Algueró et al. [59] using SPS, and by SPS Amorín et al. [60] further reduced the average grain size to $28 \mathrm{~nm}$. However, possibly due to the activation of particle surface and the high ion mobility during the SPS process, the grain size of BSPT ceramics is apparently very sensitive to the sintering temperature and mechanical pressure, thus difficult to control. Combining SPS and two-step sintering methods, we obtained BSPT samples with an average grain size ranging from $23 \mathrm{~nm}$ to $70 \mathrm{~nm}$ [61]. Moreover, adopting a practice previously used for preparing $5-8 \mathrm{~nm}$ BT ceramics $[55,56]$, we held BSPT nanopowders at $\sim 5.5 \mathrm{GPa}$ for $15 \mathrm{~min}$ at room temperature to enable plastic deformation, which allows a green body with a relative density of about $83 \%$ to form [62], then used two-step sintering (conditions in Table 3) to obtain ceramics with a grain size as small as $11 \mathrm{~nm}$. This is the finest BSPT ceramics ever reported.

TEM micrographs of these BSPT nanoceramics are shown in Fig. 5. The grain size of sample $S_{1}(6-10 \mathrm{~nm})$ lies in the same range of particle size of the starting nanopowders. The influence of $T_{1}$ is clearly important by comparing samples $S_{1}$ and $S_{4}$, which used the same $T_{2}$ and very similar holding time but different $T_{1}$, resulting in a three-fold grain size difference. However, a long holding time at the same $T_{2}$ can also cause grain growth, as evident from comparing samples $\mathrm{S}_{5}$ and $\mathrm{S}_{6}$, which used identical $T_{1}$ and $T_{2}$ but different holding time. In general, with the increase of the sintering temperature, the grain size distribution becomes wider.

Table 3 Two-step sintering schedules using BSPT green body of $83 \%$ relative density

\begin{tabular}{cccccc}
\hline Sample & $T_{1}\left({ }^{\circ} \mathrm{C}\right)$ & $T_{2}\left({ }^{\circ} \mathrm{C}\right)$ & $t(\mathrm{~h})$ & $\rho_{2}(\%)$ & GS (nm) \\
\hline $\mathrm{S}_{1}$ & 850 & 700 & 31 & 95.6 & 11 \\
$\mathrm{~S}_{2}$ & 900 & 700 & 24 & 96.6 & 21 \\
$\mathrm{~S}_{3}$ & 900 & 750 & 24 & 96.4 & 25 \\
$\mathrm{~S}_{4}$ & 950 & 700 & 24 & 95.7 & 33 \\
$\mathrm{~S}_{5}$ & 900 & 800 & 12 & 96.8 & 60 \\
$\mathrm{~S}_{6}$ & 900 & 800 & 24 & 95.9 & 80 \\
$\mathrm{~S}_{7}$ & 950 & 800 & 12 & 97.7 & 114 \\
\hline
\end{tabular}

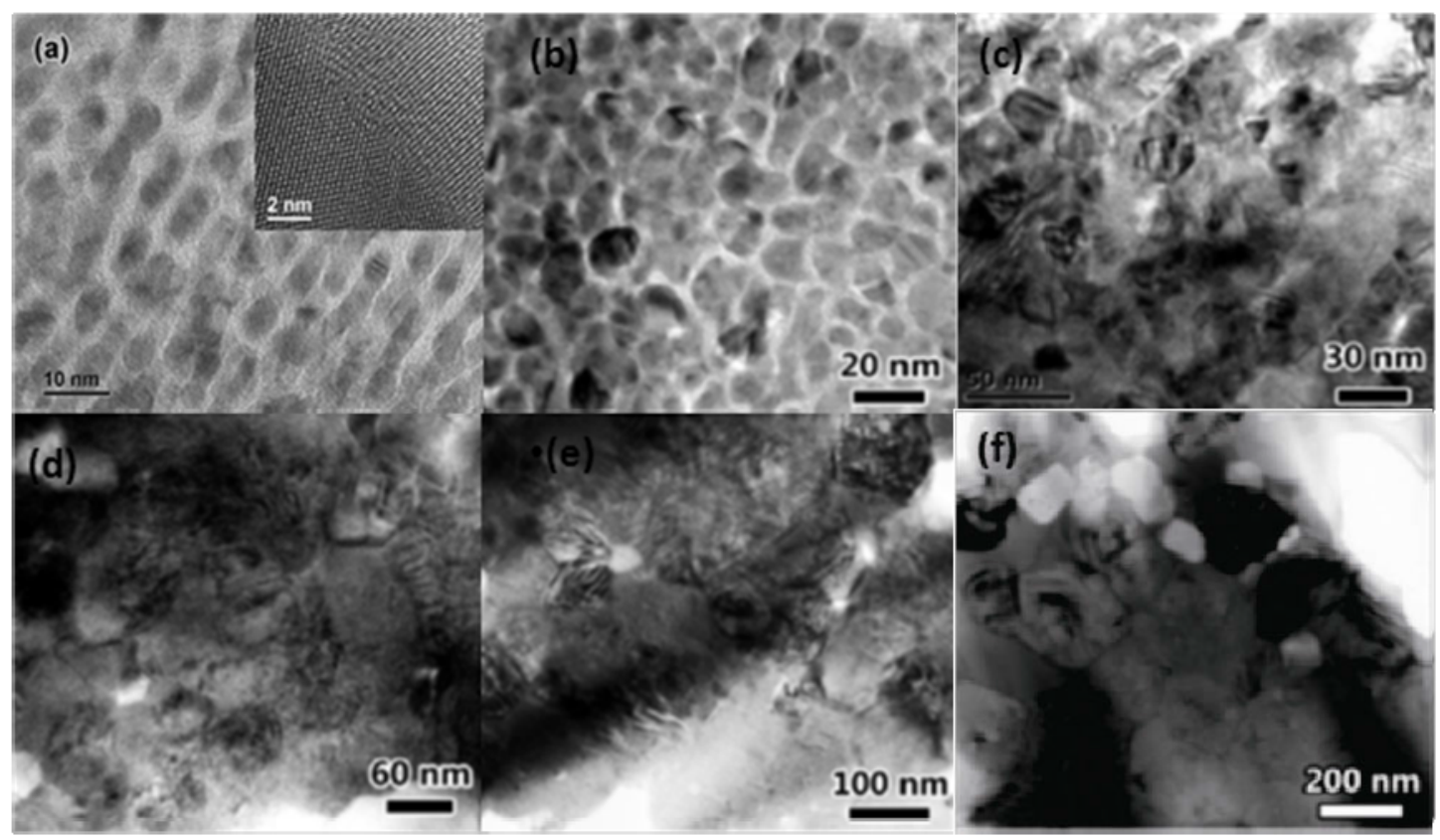

Fig. 5 TEM images of BSPT nanoceramics with grain sizes of (a) $11 \mathrm{~nm}$ (inset AC-HRTEM), (b) $21 \mathrm{~nm}$, (c) $33 \mathrm{~nm}$, (d) $60 \mathrm{~nm},(\mathrm{e}) 80 \mathrm{~nm}$ and (f) $114 \mathrm{~nm}$. 
Note that although samples $S_{1}$ and $S_{2}$ seem to have thick grain boundaries in Figs. 5(a) and 5(b), this is an imaging artifact since HRTEM imaging shown in the inset of Fig. 5(a) clearly reveals a dense and sharp grain boundary region. Such artifact is usually unimportant for imaging grains above $30 \mathrm{~nm}$, as in sample $S_{3}$, Fig. 5(c), in which the grain boundary region seems quite thin and comparable with the morphology usually observed in BSPT ceramics with micrometer-sized grains.

\section{Microstructures and properties of nano $\mathrm{BaTiO}_{3}$ ceramics}

\section{1 Microstructures and structural transitions}

\section{1. 1 Raman spectra}

Raman spectroscopy can provide a very sensitive measurement of the local crystal symmetry in powders, polycrystals and single crystals, such as $\mathrm{PbTiO}_{3}$ and $\mathrm{BaTiO}_{3}$ [63-65]. In the following, we describe our observations of Raman spectroscopy of BT powders and nanoceramics obtained using a confocal microscopic Raman spectrometer (RM2000, Renishaw, UK). To provide a reference, Raman spectra of a ceramic sample with $\mathrm{GS}=3 \mu \mathrm{m}$ were first collected. As shown in Fig. 6(a), in the temperature range of $-190-500{ }^{\circ} \mathrm{C}$, such spectra feature distinct $\mathrm{C} / \mathrm{T} / \mathrm{O} / \mathrm{R}$ dielectric transitions.

Concerning the above spectra, while symmetrycharacteristic spectra (e.g., $200{ }^{\circ} \mathrm{C}$ for the $\mathrm{C}$ phase, $100{ }^{\circ} \mathrm{C}$ for the $\mathrm{T}$ phase, $0{ }^{\circ} \mathrm{C}$ for the $\mathrm{O}$ phase and $-150{ }^{\circ} \mathrm{C}$ for the $\mathrm{R}$ phase) might be designated, the sensitivity of BT Raman spectra to both optical and microstructural details (e.g., polarization, mode-mode interference, orientation, single-domain vs. multidomain vs. polycrystal) demands a more cautious interpretation. It is known that the $310 \mathrm{~cm}^{-1}$ (sharp) and $715 \mathrm{~cm}^{-1}$ bands are forbidden in the $\mathrm{C}$ symmetry, the peak position of the $240-270 \mathrm{~cm}^{-1}$ broad band discontinuously drops during the $\mathrm{T} / \mathrm{O}$ transition, and the sharp multi-peak at $170-190 \mathrm{~cm}^{-1}$ band is an $\mathrm{R}$ characteristic, although in both $\mathrm{O}$ and $\mathrm{T}$ symmetries it still manifests as a weak, diffuse feature. Judging from the gradual nature of changes in the Raman spectra, this may also apply to other transitions suggesting the coexistence of different symmetries over a broad range of temperatures at least at the local structure level. Such ambiguity defying the use of simple symmetry-dictated selection rules is not unique to $\mathrm{BaTiO}_{3}$; a more extreme case is nominally cubic $\mathrm{ZrO}_{2}$ (stabilized by cations causing oxygen vacancies), which is well-known to have Raman bands that are forbidden in the cubic fluorite structure [66]. (This is possible because cubic $\mathrm{ZrO}_{2}$ actually has a non-fluorite-like seven-fold-coordinated local structure, as clearly revealed by extended X-ray absorption fine structure (EXAFS) spectroscopy [67-69], but these seven-fold-coordinated units are so arranged as to yield a set of cubic-fluorite-like diffraction planes that are sufficiently flat when viewed on the longer length scale by the diffracting radiation. This interpretation is perhaps also appropriate for lower-symmetry phases of $\mathrm{BaTiO}_{3}$.)

The above information allowed us to definitely identify, in the BT ceramic sample of GS $=50 \mathrm{~nm}$ (Fig. 6(b)), R symmetry at $-190-150{ }^{\circ} \mathrm{C}$ (double-peak at $170-190 \mathrm{~cm}^{-1}$ ) and $\mathrm{T} / \mathrm{O}$ transition at $50-100{ }^{\circ} \mathrm{C}$ (discontinuous shift of $240-270 \mathrm{~cm}^{-1}$ ), which are sufficient to establish the existence of all three (T/O/R) symmetries. Note that the nominally "C" spectrum at $200{ }^{\circ} \mathrm{C}$ still has weak features at $310 \mathrm{~cm}^{-1}$ and $715 \mathrm{~cm}^{-1}$ indicating $\mathrm{T}$ remnants. Therefore, the $\mathrm{C} / \mathrm{T}$ transition is rather diffuse in the polycrystal. Figures 6(c) and 6(d) show the Raman spectra of two other dense BT ceramics, with $\mathrm{GS}=8 \mathrm{~nm}$ and $5 \mathrm{~nm}$, respectively; the spectra of $5 \mathrm{~nm}$ nanopowders are also shown in Fig. 6(e). All featured peaks and their temperature evolutions seen in the Raman spectra of coarse-grain ceramics mentioned above are seen in these spectra. Furthermore, the nominally " $\mathrm{C}$ " spectrum at $290{ }^{\circ} \mathrm{C}$ still has weak features at $310 \mathrm{~cm}^{-1}$ and $715 \mathrm{~cm}^{-1}$, indicating that the $\mathrm{T}$ remnants can survive above the Curie temperature, $290{ }^{\circ} \mathrm{C}$. This suggests that all polar phases in coarse-grain ceramics still exist in nanoceramics and nanopowders, at least down to a size of $5 \mathrm{~nm}$, and that they should all undergo $\mathrm{R} \rightarrow \mathrm{O} \rightarrow \mathrm{T} \rightarrow \mathrm{C}$ phase transitions as the temperature rises $[70,71]$. In particular, the spectroscopy behavior of $5 \mathrm{~nm}$ powders and $5 \mathrm{~nm}$ dense ceramics is similar, as is the behavior of an $8 \mathrm{~nm}$ BT ceramic reported in our previous study [16].

\section{1. 2 High-resolution synchrotron $X$-ray diffraction}

Quantitative phase analysis of nanograin BT ceramics is hampered by the size broadening of diffraction peaks when using conventional diffraction techniques. Therefore, we performed high-resolution synchrotron $\mathrm{X}$-ray diffraction to study the phase evolution and 


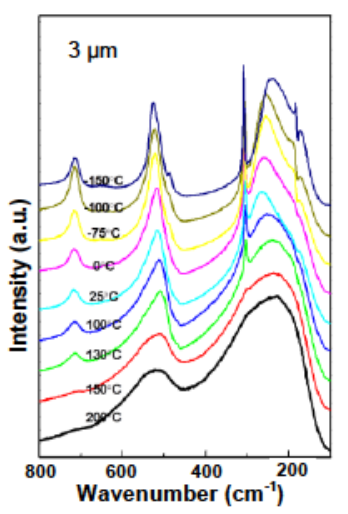

(a)

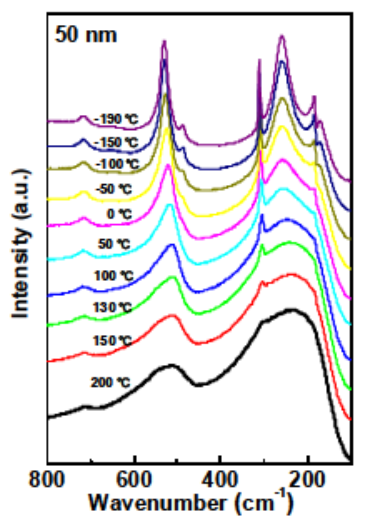

(b)

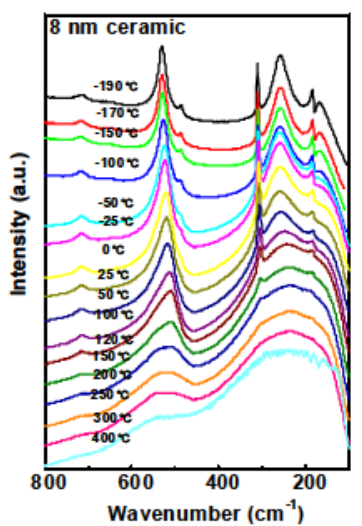

(c)

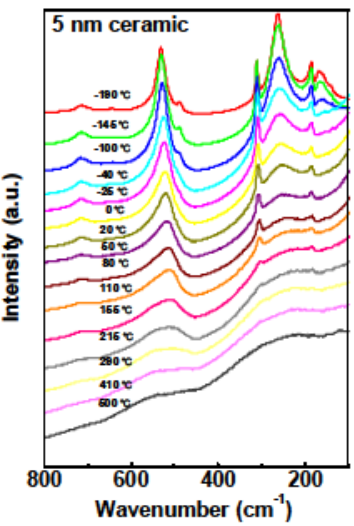

(d)

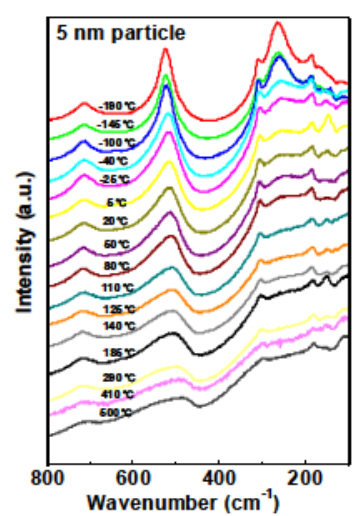

(e)

Fig. 6 Raman spectra of $\mathrm{BaTiO}_{3}$ : (a) $3 \mu \mathrm{m}$ ceramic used as reference, (b) $50 \mathrm{~nm}$ ceramic, (c) $8 \mathrm{~nm}$ ceramic, (d) $5 \mathrm{~nm}$ ceramic and (e) $5 \mathrm{~nm}$ powders. All are shown as a function of temperature from $-190{ }^{\circ} \mathrm{C}$ to $500{ }^{\circ} \mathrm{C}$.

coexistence of these ceramics $(5-100 \mathrm{~nm}$ and $150-450 \mathrm{~K})$ [72]. Our results indicate that, as temperature rises, nanograin BT still follows the same phase sequence, but the phase boundaries become more diffusive and more than one phase may coexist between $200 \mathrm{~K}$ and $450 \mathrm{~K}$. The diffraction patterns were collected at APS 11-BMB, Argonne National Laboratory, with a resolution $<2 \times 10^{-4} \Delta Q / Q$. The temperature was controlled within $\pm 1 \mathrm{~K}$. All the diffraction data were analyzed through Rietveld refinement using the General Structure Analysis System (GSAS) software package [73], including the lattice parameters, atomic positions, thermal parameters and the fractions of $\mathrm{R}, \mathrm{O}, \mathrm{T}$ and $\mathrm{C}$ phases.

For the BT ceramic of GS $=50 \mathrm{~nm}$, although there is no peak splitting in the diffraction patterns (inset in Fig. 7), the non-monotonic temperature dependence of the diffraction peak width $\delta Q$ reveals underlying phase transitions (errors in Fig. 7 are much smaller than the size of the symbols and the width of the diffraction curves). Specifically, since peak splitting in single crystal is most pronounced at the (200) reflection in the (high-temperature) $\mathrm{T}$ phase but most pronounced at the (220) reflection in the (low-temperature) R phase [74], it is unlikely to be a mere coincidence that the same trend is observed in Fig. 7 in the temperature variation of $\delta Q$ of the "unsplit" (200) reflections and (220) reflections. If instead we take $\delta Q$ as being caused by the combined effect of peak splitting and phase mixing, we can analyze the $\delta Q$ data to obtain the phase fractions; this is shown as a function of temperature in Fig. 8. Quite similar results were also obtained for a

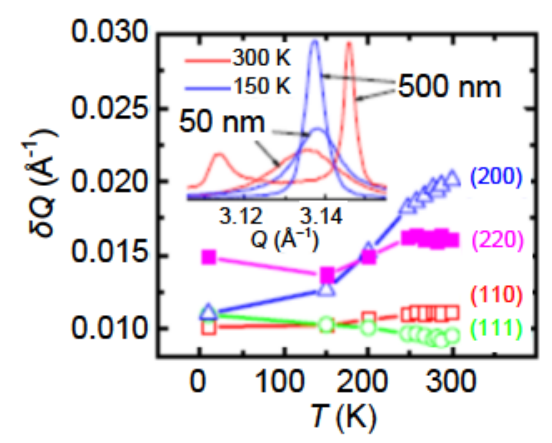

Fig. 7 Synchrotron $\mathrm{X}$-ray structure analysis of nanograin $\mathrm{BaTiO}_{3}$ ceramic $(\mathrm{GS}=50 \mathrm{~nm})$. 


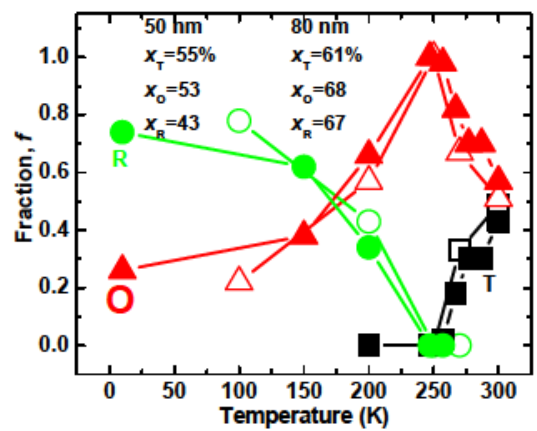

Fig. 8 Phase analysis of nanograin $\mathrm{BaTiO}_{3}$ ceramics $(\mathrm{GS}=50 \mathrm{~nm}$ and $80 \mathrm{~nm})$.

ceramic of GS $=80 \mathrm{~nm}$.

A parallel study of BT nanopowders was also performed using the same diffraction method. Table 4 gives the phase fractions of BT nanopowders with particle size $5-100 \mathrm{~nm}$ at various temperatures. Except for the $\mathrm{R}$ phase at $150 \mathrm{~K}$, all other diffraction patterns must be fit with two or three phases, $\mathrm{R}+\mathrm{O}, \mathrm{R}+\mathrm{O}+\mathrm{T}$, $\mathrm{O}+\mathrm{T}$ and $\mathrm{O}+\mathrm{T}+\mathrm{C}$, in the sequence of increasing temperature. Compared to coarse-grain ceramics and coarse powders, the temperature range of $\mathrm{R}, \mathrm{O}, \mathrm{T}$ and $\mathrm{C}$ phases are all extended, resulting in phase coexistence over a wide temperature range. This trend is consistent with the observation in nanograin ceramics. In particular, with decreasing particle size or grain size, the temperature of the $\mathrm{C}$ to $\mathrm{T}$ transition decreases, while the temperatures of the $\mathrm{R}$ to $\mathrm{O}$ and $\mathrm{O}$ to $\mathrm{T}$ transitions increase. Meanwhile, although the phase boundaries become diffuse in Fig. 9, even the smallest sized BT powders are still ferroelectric over a wide temperature range, making them potentially suitable for practical, ferroelectricity-related applications.

Nano BT powders and ceramics with very small sizes and very large surface areas are likely to have a large number of defects on the surface and grain boundaries, which may give rise to compressive stresses. These internal stresses may alter relative phase stability in a complicated manner $[18,75]$, causing shift of phase boundary, diffuse transition and phase coexistence. (Long-range shear stresses have also been speculated in the literature, although they are unlikely since they can be easily relaxed by grain boundary dislocations and related defect constructs.) In addition, there seems to be some evidence that the evolution may not be monotonic, with possible phase reentrance as shown in Fig. 10 for $20 \mathrm{~nm}$ BT powders, suggesting that very small BT powders may sustain ferroelectricity after all. Further experimental studies (which may be challenging) to place these theoretical hypotheses and initial observations on a firmer footing are needed to reach a better understanding of ferroelectricity in a nanograin/nanopowder setting.

\section{2 Size effect on ceramic properties}

\section{2. 1 Dielectric and ferroelectric properties}

In the coarse-grain regime, relative dielectric constant $K$ has a well-known maximum at GS $\approx 1 \mu \mathrm{m}$ [9], below which $K$ decreases since there is no domain wall movement. Whether nanograin BT can provide an elevated $K$ has been repeatedly questioned in the literature, but no reliable data over a large range of grain size exist in the past. Using high-purity two-step sintered ceramic samples with grain size from nanometer to micrometer, we have investigated this subject. To remove the influence of moisture, which is especially pronounced at small grain size, dielectric measurements reported below were all performed in vacuum after the samples were first baked in situ.

Table 4 Phase fractions of nano $\mathrm{BaTiO}_{3}$ powders as functions of particle size and temperature (unit: \%)

\begin{tabular}{|c|c|c|c|c|c|c|c|}
\hline \multirow{2}{*}{ Particle size } & \multicolumn{7}{|c|}{ Tempertature } \\
\hline & $150 \mathrm{~K}$ & $200 \mathrm{~K}$ & $250 \mathrm{~K}$ & $300 \mathrm{~K}$ & $350 \mathrm{~K}$ & $400 \mathrm{~K}$ & $450 \mathrm{~K}$ \\
\hline \multirow{2}{*}{$100 \mathrm{~nm}$} & $\mathrm{R}$ & $\mathrm{R}+\mathrm{O}$ & $\mathrm{R}+\mathrm{O}+\mathrm{T}$ & $\mathrm{O}+\mathrm{T}$ & $\mathrm{O}+\mathrm{T}$ & $\mathrm{O}+\mathrm{T}+\mathrm{C}$ & $\mathrm{O}+\mathrm{T}+\mathrm{C}$ \\
\hline & $(100)$ & $(64+36)$ & $(25+25+50)$ & $(25+75)$ & $(20+80)$ & $(32+54+14)$ & $(28+24+48)$ \\
\hline \multirow{2}{*}{$50 \mathrm{~nm}$} & $\mathrm{R}$ & $\mathrm{R}+\mathrm{O}$ & $\mathrm{R}+\mathrm{O}+\mathrm{T}$ & $\mathrm{O}+\mathrm{T}$ & $\mathrm{O}+\mathrm{T}$ & $\mathrm{O}+\mathrm{T}+\mathrm{C}$ & $\mathrm{O}+\mathrm{T}+\mathrm{C}$ \\
\hline & $(100)$ & $(60+40)$ & $(33+17+50)$ & $(38+62)$ & $(33+67)$ & $(33+44+23)$ & $(17+33+50)$ \\
\hline \multirow{2}{*}{$40 \mathrm{~nm}$} & $\mathrm{R}$ & $\mathrm{R}+\mathrm{O}$ & $\mathrm{R}+\mathrm{O}+\mathrm{T}$ & $\mathrm{O}+\mathrm{T}$ & $\mathrm{O}+\mathrm{T}$ & $\mathrm{O}+\mathrm{T}+\mathrm{C}$ & $\mathrm{O}+\mathrm{T}+\mathrm{C}$ \\
\hline & $(100)$ & $(58+42)$ & $(22+13+65)$ & $(47+53)$ & $(38+62)$ & $(21+44+35)$ & $(15+33+52)$ \\
\hline \multirow{2}{*}{$20 \mathrm{~nm}$} & $\mathrm{R}$ & $\mathrm{R}+\mathrm{O}$ & $\mathrm{R}+\mathrm{O}+\mathrm{T}$ & $\mathrm{O}+\mathrm{T}$ & $\mathrm{O}+\mathrm{T}$ & $\mathrm{O}+\mathrm{T}+\mathrm{C}$ & $\mathrm{O}+\mathrm{T}+\mathrm{C}$ \\
\hline & $(100)$ & $(56+44)$ & $(21+8+71)$ & $(50+50)$ & $(41+59)$ & $(20+40+40)$ & $(6+31+63)$ \\
\hline \multirow{2}{*}{$10 \mathrm{~nm}$} & $\mathrm{R}$ & $\mathrm{R}+\mathrm{O}$ & $\mathrm{R}+\mathrm{O}+\mathrm{T}$ & $\mathrm{O}+\mathrm{T}$ & $\mathrm{O}+\mathrm{T}$ & $\mathrm{O}+\mathrm{T}+\mathrm{C}$ & $\mathrm{O}+\mathrm{T}+\mathrm{C}$ \\
\hline & $(100)$ & $(63+37)$ & $(45+19+36)$ & $(38+62)$ & $(32+68)$ & $(30+44+26)$ & $(18+33+49)$ \\
\hline \multirow{2}{*}{$5 \mathrm{~nm}$} & $\mathrm{R}$ & $\mathrm{R}+\mathrm{O}$ & $\mathrm{R}+\mathrm{O}+\mathrm{T}$ & $\mathrm{O}+\mathrm{T}$ & $\mathrm{O}+\mathrm{T}$ & $\mathrm{O}+\mathrm{T}+\mathrm{C}$ & $\mathrm{O}+\mathrm{T}+\mathrm{C}$ \\
\hline & (100) & $(80+20)$ & $(50+25+25)$ & $(33+67)$ & $(23+77)$ & $(32+48+20)$ & $(11+42+47)$ \\
\hline
\end{tabular}



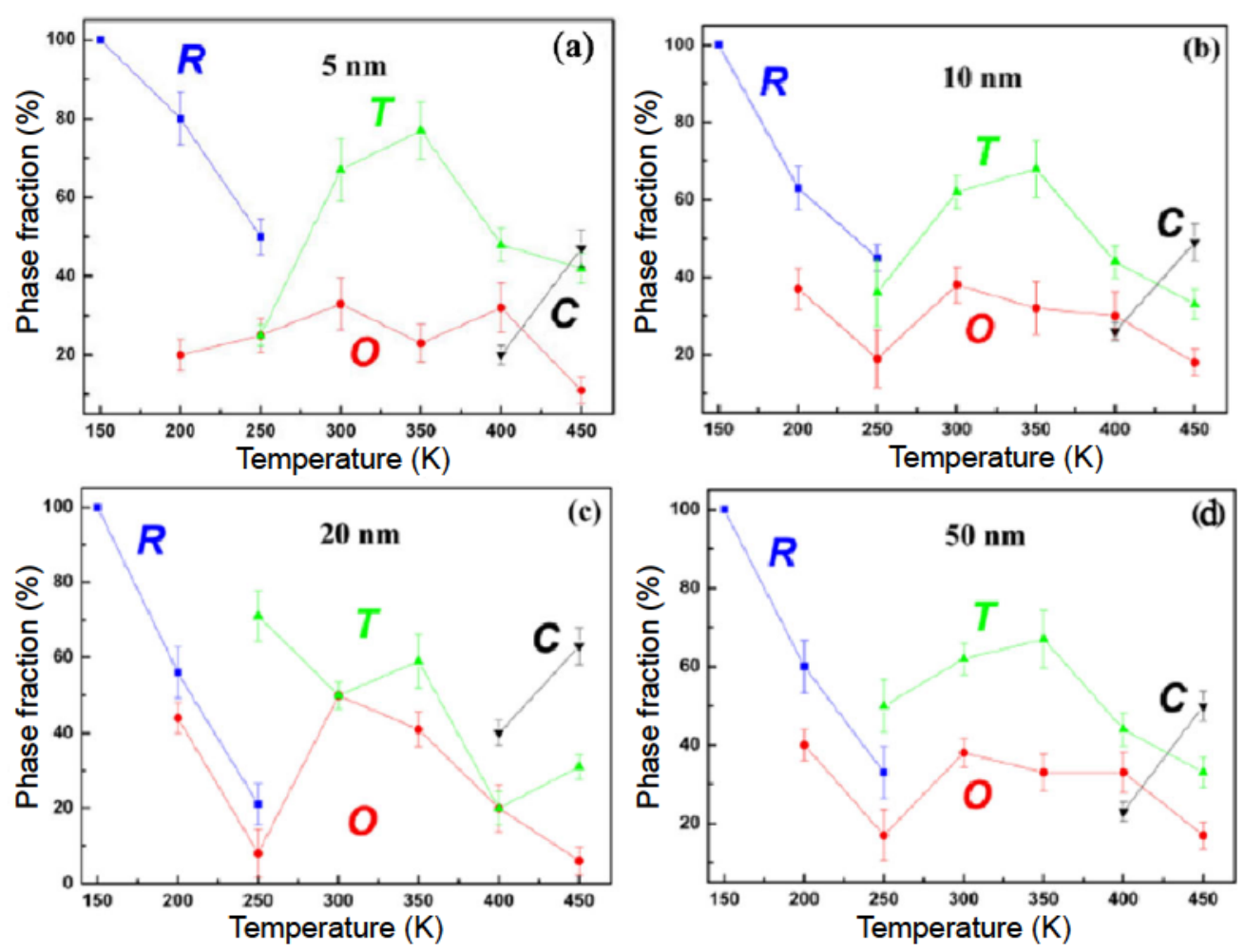

Fig. 9 Phase fraction evolutions of $\mathrm{BaTiO}_{3}$ powders as a function of temperature with particles sizes of (a) $5 \mathrm{~nm}$, (b) $10 \mathrm{~nm}$, (c) $20 \mathrm{~nm}$ and (d) $50 \mathrm{~nm}$.

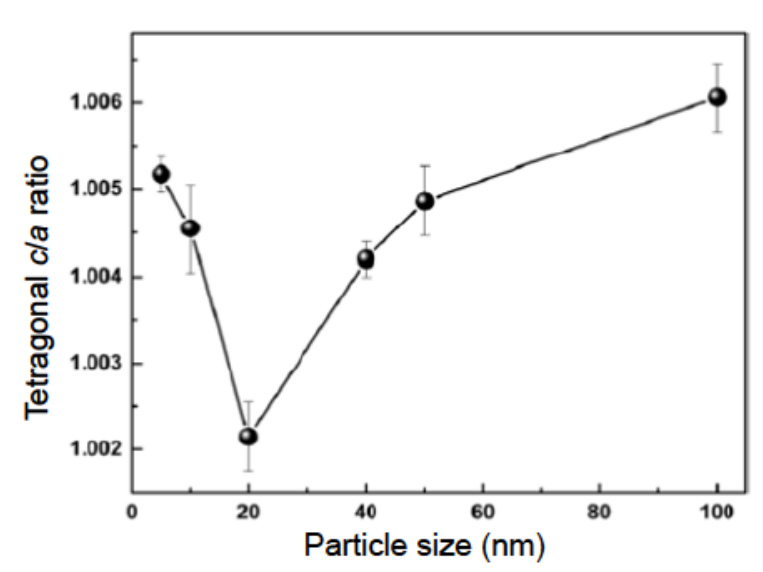

Fig. $10 \quad c / a$ ratio of tetragonal phase $\mathrm{BaTiO}_{3}$ powders as a function of particle size at room temperature.

As shown in Fig. 11, all the temperature spectra of $K$ show a discernible $\mathrm{C}$ to $\mathrm{T}$ phase transition. In comparison, the low-temperature transitions are much weaker and broader. At smaller grain size, they appear as diffuse humps on a positively sloping background that in part is the low-temperature tail of the $\mathrm{C} / \mathrm{T}$ transition. We identify the transition temperatures at the minimal $\mathrm{d}^{2} K / \mathrm{d} T^{2}$, since this procedure largely removes the distortion caused by the sloping background (its $\mathrm{d}^{2} K / \mathrm{d} T^{2} \approx 0$ ). As shown in Fig. 12, over the grain size range of $50-800 \mathrm{~nm}$, the transition temperatures determined show a steady decrease with grain size of about $12{ }^{\circ} \mathrm{C}$ for the $\mathrm{C} / \mathrm{T}$ transition, in contrast to a steady increase of a similar amount for the $\mathrm{T} / \mathrm{O}$ transition and about $20^{\circ} \mathrm{C}$ for the $\mathrm{O} / \mathrm{R}$ transition. The temperature for the $\mathrm{C} / \mathrm{T}$ transition of the $50 \mathrm{~nm}$ sample $\left(115^{\circ} \mathrm{C}\right)$ agrees with that reported for an SPS BT of nominally the same grain size [76]. Meanwhile, although the $\mathrm{T} / \mathrm{O} / \mathrm{R}$ transitions have not been reported before for $\mathrm{GS}<300 \mathrm{~nm}$, the trend of increasing transition temperature with smaller grain size is the

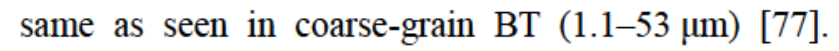
Moreover, identical temperature spectra of relative dielectric constant with $\mathrm{C} / \mathrm{T} / \mathrm{O} / \mathrm{R}$ transitions in cooling and heating were observed (not shown), indicating the behavior is rather robust. Therefore, although for smaller grain size (down to $50 \mathrm{~nm}$ ) all transitions are very broad indeed, nanograin ceramics still have structural distortions following similar trends as those of coarse-grain ceramics. 


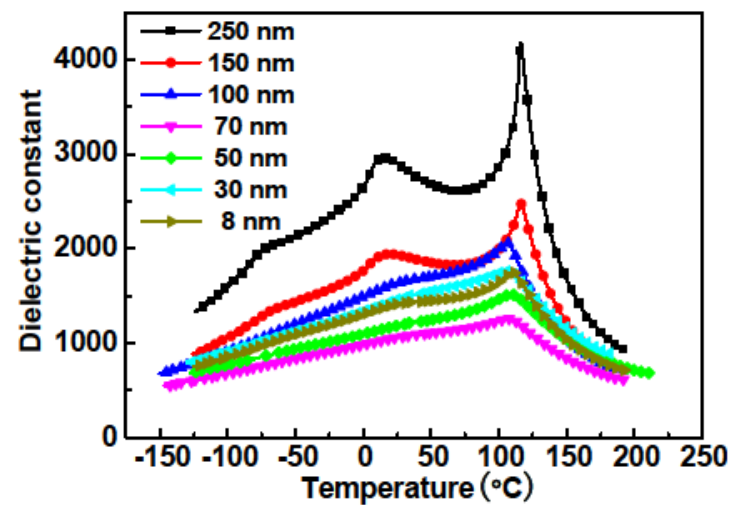

Fig. 11 Temperature spectra of dielectric constant for BT ceramics during cooling.

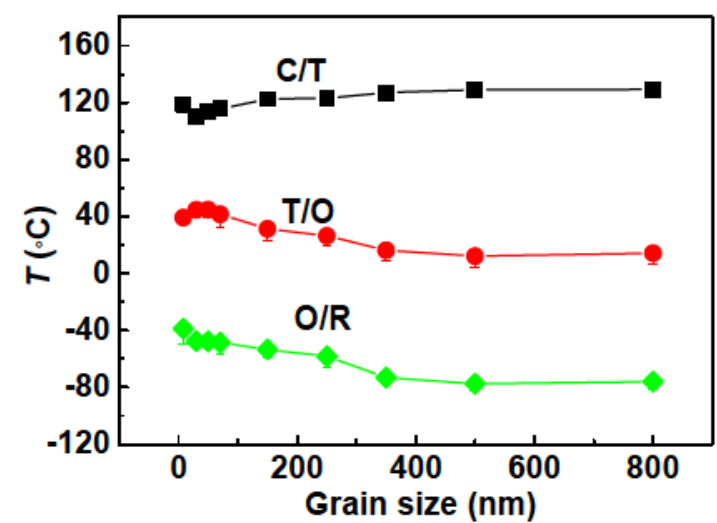

Fig. 12 Temperatures of $C / T, T / O$ and $O / R$ transitions versus grain size.

At the smallest grain size limit investigated in this study, the $8 \mathrm{~nm}$ ceramic does show excellent dielectric properties with three discernible peaks (arrows in Fig. 13) corresponding to the three phase transitions. These peaks are obviously more diffuse than in the GS $=150$ $\mathrm{nm}$ sample (Fig. 11), but interestingly their frequency dependence is very weak below $T_{\mathrm{C}}$ and nonexistent above $T_{\mathrm{C}}$. So the diffuseness cannot be attributed to a broad distribution of polarization relaxation time, i.e., it is not a relaxor. The small dielectric loss (typically< $2 \%)$ is consistent with the high resistivity (7.8× $10^{11} \Omega \cdot \mathrm{cm}$ ) and the dense, single-phase microstructure revealed by the TEM micrograph (Fig. 3(a)). On the other hand, despite the robust dielectric properties, the switchable polarization measured by integrating the depolarization current after poling (under $0.1 \mathrm{MV} / \mathrm{m}$ during cooling from $500 \mathrm{~K}$ to $77 \mathrm{~K}$ ) is very small in the $\mathrm{GS}=8 \mathrm{~nm}$ sample (Fig. 14), indicating its ferroelectricity is severely clamped, making temperature-dependent spontaneous depolarization difficult.

The technological driving force toward nanograin

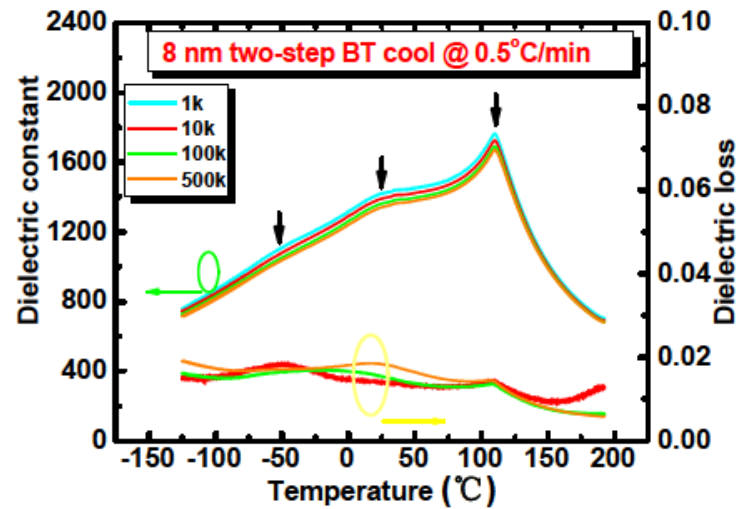

Fig. 13 Dielectric spectra of $8 \mathrm{~nm}$ BT ceramic at different frequencies $\left(T_{\mathrm{C}}=118^{\circ} \mathrm{C}\right)$.

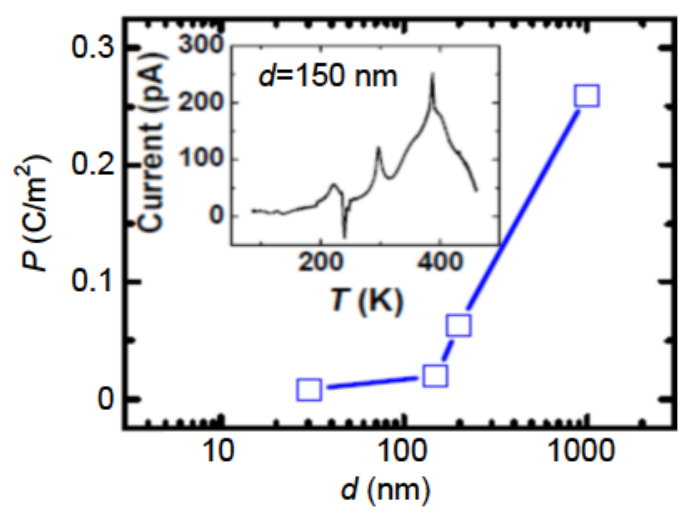

Fig. 14 Grain size effect on switchable polarization of BT ceramics. Inset: depolarization current with peaks at transition temperatures.

MLCC ceramics comes from not only component miniaturization but also performance. The figure of merit of a capacitor may be defined as the capacitance per unit volume, scaled with $K / t^{2}$, where $t$ is the layer thickness of the capacitor. In very thin capacitors, dielectric breakdown is a concern, so the stored charge per unit volume at the breakdown electrical field $E_{\mathrm{b}}$, $K E_{\mathrm{b}} / t$, may be taken as an alternative figure of merit. Either measure demands thinner layers, but thinner layers must have a correspondingly smaller ceramic grain size $(\mathrm{GS}=d)$ to ensure reliable properties and smooth layer interfaces. Typically $t / d=6-10$. Therefore, the figure of merit scales with $K / d$ since $E_{\mathrm{b}}$ and $t / d$ are nearly constant. As described above, undoped BT ceramic of GS $=8 \mathrm{~nm}$ displays a robust $K$-temperature performance, with a very low dielectric loss and clear evidence of multiple dielectric/ferroelectric transitions. This nanograin ceramic exhibits a higher figure of merit at $25^{\circ} \mathrm{C}$ than the state-of-the-art MLCC ceramics featuring $\mathrm{GS}=100 \mathrm{~nm}$ (Fig. 15). Such reassuring results encourage the continuing march of the MLCC development down the road of nanograin ceramics. 


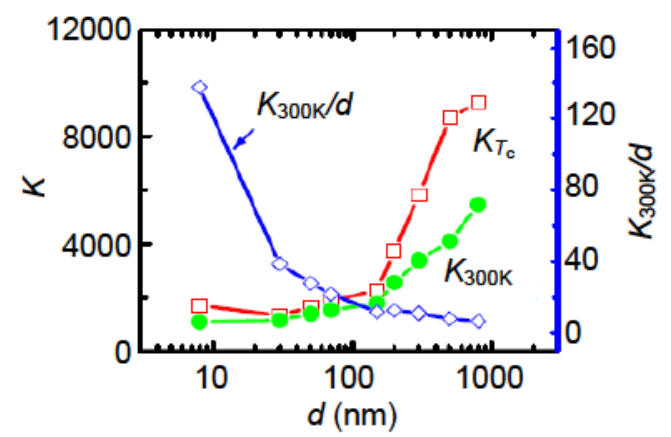

Fig. 15 Relative dielectric constant $K$ and figure of merit $(K / d)$ of BT ceramics of different grain size $(\mathrm{GS}=d)$.

\section{2.2 Piezoelectric properties}

BT-based ceramics have been known to show modest piezoelectric activity, with a piezoelectric coefficient $\left(d_{33}\right)$ of about $190 \mathrm{pC} / \mathrm{N}$, much less than that of commercial PZT ceramics [78]. Recently, high $d_{33}$ values $(338 \mathrm{pC} / \mathrm{N}, 460 \mathrm{pC} / \mathrm{N}$ and $500 \mathrm{pC} / \mathrm{N})$ have been obtained in BT ceramics at $\mathrm{GS}=0.94 \mu \mathrm{m}, 1.6 \mu \mathrm{m}$ and $1 \mu \mathrm{m}$, respectively [79-81]. This is believed to be related to the domains in the ceramics. In addition, it is known that $d_{33}$ values decrease from $420 \mathrm{pC} / \mathrm{N}$ to $185 \mathrm{pC} / \mathrm{N}$ when the average grain size increases from $7 \mu \mathrm{m}$ to $19 \mu \mathrm{m}$, while the average domain width remains approximately constant at around $480 \mathrm{~nm}$ [82]. Therefore, the piezoelectric properties of BT can be enhanced by controlling grain size and the corresponding domain structure. Since there is little information about the grain size dependence of piezoelectric properties and domain structures in BT ceramics at grain size below $700 \mathrm{~nm}$, we have undertaken the following study using a similar series of dense BT ceramics as those described above for dielectric properties [57].

Table 5 lists the relative density $\left(\rho_{0}\right)$, average grain size, macroscopic $d_{33}$ and $K$ of various BT ceramics studied. The grain size dependence of $d_{33}$ is shown in Fig. 16, which confirms that $d_{33}$ is enhanced by a decreasing grain size, but the maximum $d_{33}(519 \mathrm{pC} / \mathrm{N})$ is reached at around $1 \mu \mathrm{m}$ below which it rapidly drops with a further decrease in grain size. The $d_{33}$ values from previous studies [79-84] are also plotted in Fig. 16 for comparison; unlike our data they failed to give a clear indication of the $d_{33}$ maximum because their smallest grain size was limited to about $1 \mu \mathrm{m}$. Thus, using the TSS technology to obtain finer-grain BT ceramics, we have firmly established the range of optimal grain size for $d_{33}: d_{33}=400-519 \mathrm{pC} / \mathrm{N}$ at $\mathrm{GS}=500-1000 \mathrm{~nm}$ - the value of $519 \mathrm{pC} / \mathrm{N}$ being superior to all those reported in prior studies.

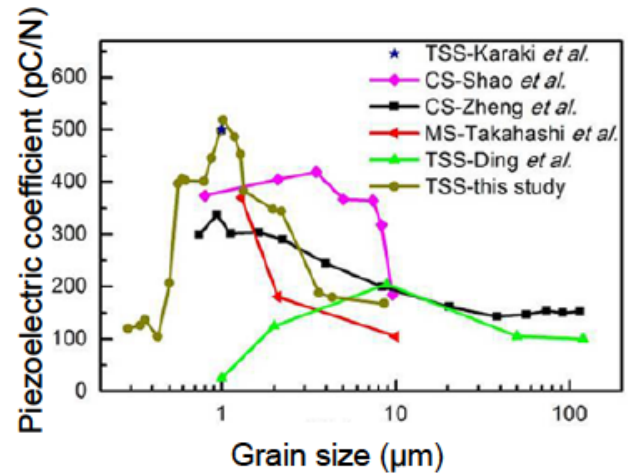

Fig. $16 d_{33}$ dependence on grain size of BT ceramics (CS, MS and TSS are abbreviations of conventional sintering, microwave sintering and two-step sintering, respectively).

Table 5 Relative density, average grain size, piezoelectric coefficient $\boldsymbol{d}_{33}$ and dielectric constant $K$ for various $\mathrm{BaTiO}_{3}$ ceramics prepared by TSS, using $T_{1}$ and $T_{2}$ (for $t_{2}$ ) schedules

\begin{tabular}{crccccc}
\hline$T_{1}\left({ }^{\circ} \mathrm{C}\right)$ & $T_{2}\left({ }^{\circ} \mathrm{C}\right)$ & $t_{2}(\mathrm{~h})$ & $\rho_{0}(\%)$ & $\mathrm{GS}(\mu \mathrm{m})$ & $K$ & $d_{33}(\mathrm{pC} / \mathrm{N})$ \\
\hline 1250 & 800 & 24 & 95.4 & 0.29 & 3660 & 120 \\
1250 & 850 & 24 & 95.7 & 0.34 & 3883 & 126 \\
1250 & 900 & 24 & 96.4 & 0.36 & 4133 & 137 \\
1250 & 950 & 24 & 96.6 & 0.43 & 4207 & 105 \\
1250 & 1000 & 24 & 96.8 & 0.50 & 4794 & 207 \\
1280 & 800 & 24 & 96.6 & 0.56 & 4839 & 397 \\
1280 & 850 & 24 & 96.9 & 0.59 & 5034 & 407 \\
1280 & 900 & 24 & 96.7 & 0.62 & 5126 & 403 \\
1280 & 950 & 24 & 97.1 & 0.79 & 5144 & 401 \\
1280 & 1000 & 24 & 96.5 & 0.87 & 5284 & 446 \\
1310 & 800 & 24 & 96.4 & 0.99 & 6079 & 498 \\
1310 & 850 & 24 & 96.4 & 1.02 & 6487 & 519 \\
1310 & 900 & 24 & 96.8 & 1.19 & 5366 & 486 \\
1310 & 950 & 24 & 98.9 & 1.28 & 5018 & 453 \\
1310 & 1000 & 24 & 98.6 & 1.34 & 4860 & 383 \\
1340 & 900 & 24 & 98.0 & 1.97 & 4072 & 348 \\
1340 & 950 & 24 & 97.4 & 2.21 & 3733 & 344 \\
1340 & 1000 & 24 & 96.9 & 3.64 & 2137 & 188 \\
1340 & 1050 & 24 & 96.8 & 4.32 & 1834 & 180 \\
1340 & 1100 & 24 & 96.5 & 8.61 & 1650 & 168 \\
\hline
\end{tabular}

It is known that the piezoelectric properties of ceramics may have an extrinsic contribution due to the motion of ferroelectric domain walls $[85,86]$. Using computer simulation, Ahluwalia et al. [87] investigated a model ferroelectric and showed that the piezoelectric coefficient is enhanced by reducing the domain size. Supporting experimental evidence was observed by Wada et al. [88] in BT single crystals and by Takahashi et al. [89] in microwave-sintered BT ceramics, correlating superior piezoelectric properties to small domain sizes. To investigate the grain size effect on $d_{33}$, we examined the domain configurations of BT ceramics as a function of grain size using TEM [57]. The domain width $(d w)$ is found to increase with grain size as shown in Fig. 17, and some examples of domain structures are shown in Fig. 18 covering the 
grain size range from $8 \mathrm{~nm}$ to $2 \mu \mathrm{m}$. Remarkably, nanodomains with size of several to $10 \mathrm{~nm}$ are still observed in BT ceramics of the finest grain size, of $8 \mathrm{~nm}$. Moreover, using high-sensitivity piezoresponse force microscopy as a local probe (SPI 4000/ SPA300HV, Seiko, Japan, operated at $2 \mathrm{~V}$ AC rootmean-square voltage at $5 \mathrm{kHz}$, in addition to a DC bias of $\pm 10 \mathrm{~V}$ ) [16], we observed polarization switching

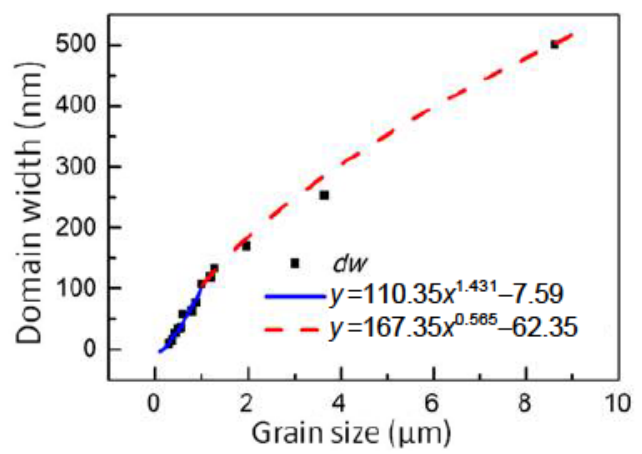

Fig. 17 Domain size dependence of BT ceramics with different grain size. A two-segment curve fit is also shown along with the fitting parameters. and piezoelectricity in BT nanoceramics at room temperature. Apparently, even with the finest grain size $(5 \mathrm{~nm})$, the very high local field near the tip of an atomic force microscope (AFM) can induce ferroelectric hysteresis loops such as those shown in Fig. 19. However, the requisite high field (to overcome the coercive field) when GS $<1 \mu \mathrm{m}$ proves inaccessible in bulk ceramics making bulk ferroelectricity and piezoelectricity impossible to manifest.

When GS $>1 \mu \mathrm{m}$, it is a common observation that the $90^{\circ}$ domain width decreases with decreasing grain size. The finer domain width means a larger contribution of domain wall movement to the piezoelectric response, which is favorable for improved piezoelectric properties [90]. On the other hand, when GS $<1 \mu \mathrm{m}$, the domain density actually deceases due to the increasing volume fraction of interfaces themselves (domain walls and grain boundaries) and the emergence of monodomains, which coincides with the decrease of $d_{33}$ with decreasing grain size. Moreover, in nanograin ceramics, internal stresses are likely to be another reason that
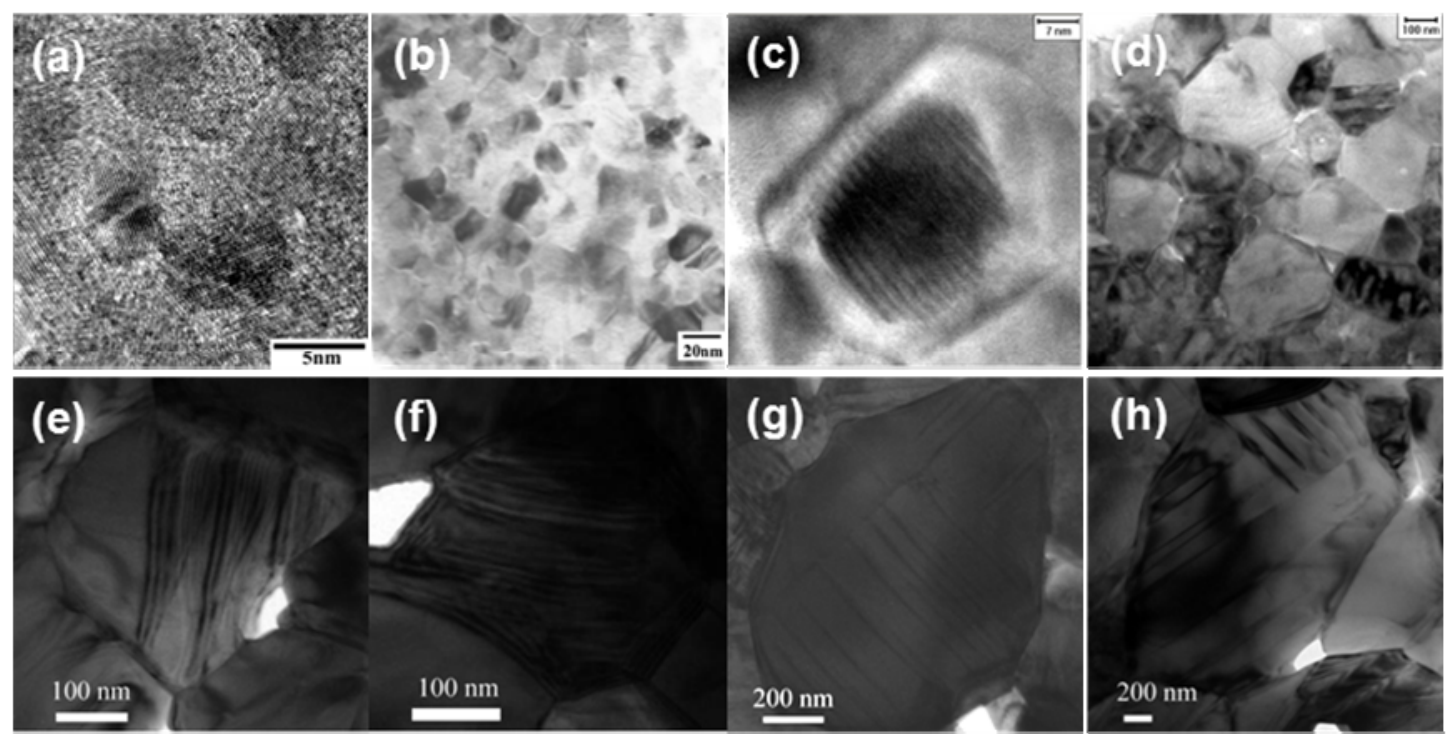

Fig. 18 TEM micrographs of domain structures of BT ceramics: (a) $8 \mathrm{~nm}$, (b) $20 \mathrm{~nm}$, (c) $50 \mathrm{~nm}$, (d) $100 \mathrm{~nm}$, (e) 290 $\mathrm{nm}$, (f) $360 \mathrm{~nm}$, (g) $990 \mathrm{~nm}$ and (h) $1970 \mathrm{~nm}$.

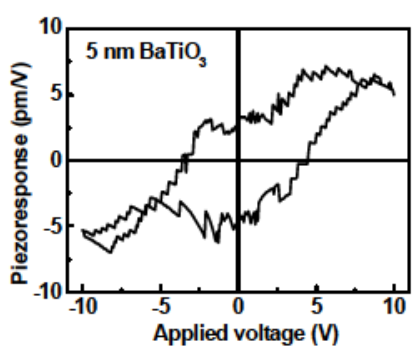

(a) $5 \mathrm{~nm}$

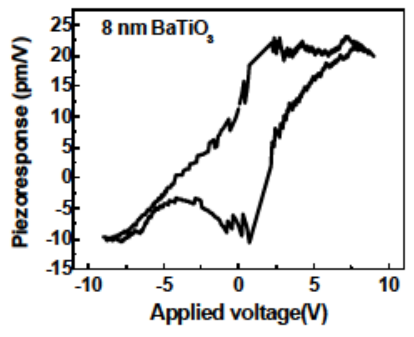

(b) $8 \mathrm{~nm}$

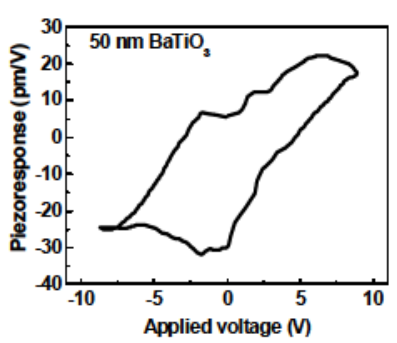

(c) $50 \mathrm{~nm}$

Fig. 19 Typical piezoelectric loops of dense BT ceramics of various grain sizes: (a) $5 \mathrm{~nm}$, (b) $8 \mathrm{~nm}$ and (c) $50 \mathrm{~nm}$. 
may cause clamping of domains and domain walls. Two-step sintering is nevertheless advantageous since it allows a very precise control of the grain size with excellent size uniformity. This will in turn allow better optimization of piezoelectric response of BT ceramics, which is of considerable interest because BT is lead-free.

\section{Microstructures and properties of nano $(1-x) \mathrm{BiScO}_{3}-x \mathrm{PbTiO}_{3}$ ceramics}

\section{1 Microstructures}

As described in Section 2.2, dense BSPT ceramics with an average grain size from $1 \mu \mathrm{m}$ to $11 \mathrm{~nm}$ have been prepared by two-step sintering. Figure 20 shows the X-ray diffraction (XRD) patterns of BSPT ceramics with MPB composition at room temperature. For GS $>60 \mathrm{~nm}$, peak splitting is obvious [31]. Although this is not seen in finer-grain samples because of peak broadening, asymmetry is evident indicating a similar tetragonal distortion still exists in all the samples.

High-resolution synchrotron XRD from $25{ }^{\circ} \mathrm{C}$ to $500{ }^{\circ} \mathrm{C}$ was also obtained for BSPT ceramics with grain size from $11 \mathrm{~nm}$ to $114 \mathrm{~nm}$. Various structural models were used to fit the data. For example, one can model the XRD of nanograin BSPT by letting it contain a paraelectric cubic phase (perhaps in the grain boundary region) in addition to a tetragonal phase: as the grain size reduces, the volume fraction of the grain boundary region and hence the cubic phase increase. The refinement results based on different structural models for the $11 \mathrm{~nm}$ BSPT sample are listed in Table 6. According to the agreement factors $R_{\mathrm{wp}}$ and GOF, the $\mathrm{T}+\mathrm{M}$ ( $\mathrm{T}$ for tetragonal and $\mathrm{M}$ for monoclinic) phase model was better than the $\mathrm{T}+\mathrm{R}$ ( $\mathrm{R}$ for rhombohedral) phase model, and the addition of the cubic (C) phase also improved the refinement, with the $c / a$ ratio of tetragonal distortion slightly increased after the addition [91]. Therefore, the synchrotron data

Table 6 Comparison of refined crystallographic data and agreement factors for BSPT nanoceramics with $\mathrm{GS}=11 \mathrm{~nm}$ at $T=300 \mathrm{~K}$

\begin{tabular}{|c|c|c|c|c|c|c|}
\hline \multirow[b]{2}{*}{ Model } & \multirow{2}{*}{$\begin{array}{c}\text { Phase } \\
\text { fraction } \\
(\%)\end{array}$} & \multicolumn{3}{|c|}{ Lattice constant $\left(\AA \cdot\left(^{\circ}\right)^{-1}\right)$} & \multirow[b]{2}{*}{$\begin{array}{l}R_{\text {wp }} \\
(\%)\end{array}$} & \multirow{2}{*}{$\begin{array}{l}\text { GOF } \\
(\%)\end{array}$} \\
\hline & & $\mathrm{T}(P 4 \mathrm{~mm})$ & $\begin{array}{c}\mathrm{R}(\mathrm{R} 3 \mathrm{~m}) / \\
\mathrm{M}(\mathrm{Cm})\end{array}$ & $\mathrm{C}(P m 3 m)$ & & \\
\hline \multirow{2}{*}{$\mathrm{T}+\mathrm{R}$} & \multirow{2}{*}{$55 / 45$} & $c=4.0472$ & $a=4.0252$ & \multirow{2}{*}{ 一 } & \multirow{2}{*}{3.61} & \multirow{2}{*}{9.48} \\
\hline & & $a=4.0154$ & $\beta=89.94$ & & & \\
\hline \multirow{2}{*}{$\mathrm{T}+\mathrm{R}+\mathrm{C}$} & \multirow{2}{*}{$33 / 28 / 39$} & $c=4.0645$ & $a=4.0273$ & \multirow{2}{*}{$a=4.02761$} & \multirow{2}{*}{2.89} & \multirow{2}{*}{6.11} \\
\hline & & $a=4.0056$ & $\beta=89.99$ & & & \\
\hline \multirow{4}{*}{$\mathrm{T}+\mathrm{M}$} & \multirow{4}{*}{$53 / 47$} & & $a=5.6865$ & \multirow{4}{*}{ - } & \multirow{4}{*}{2.56} & \multirow{4}{*}{4.81} \\
\hline & & $c=4.0434$ & $b=5.6459$ & & & \\
\hline & & $a=4.0168$ & $c=4.0777$ & & & \\
\hline & & & $\beta=89.94$ & & & \\
\hline \multirow{4}{*}{$\mathrm{T}+\mathrm{M}+\mathrm{C}$} & \multirow{4}{*}{$28 / 42 / 30$} & & $a=5.6927$ & \multirow{4}{*}{$a=4.0281$} & \multirow{4}{*}{2.39} & \multirow{4}{*}{4.19} \\
\hline & & $c=4.0524$ & $b=5.6426$ & & & \\
\hline & & $a=4.0121$ & $c=4.0803$ & & & \\
\hline & & & $\beta=89.96$ & & & \\
\hline \multirow{4}{*}{$\begin{array}{c}\mathrm{T}+\mathrm{M} \\
(1.5 \mu \mathrm{m})\end{array}$} & \multirow{4}{*}{$34 / 66$} & & $a=5.6592$ & \multirow{4}{*}{ - } & \multirow{4}{*}{7.87} & \multirow{4}{*}{3.38} \\
\hline & & $c=4.0852$ & $b=5.6589$ & & & \\
\hline & & $a=3.9929$ & $c=4.0589$ & & & \\
\hline & & & $\beta=89.673$ & & & \\
\hline
\end{tabular}

T: $P 4 m m ; \mathrm{R}: \mathrm{R3m} ; \mathrm{M}: \mathrm{Cm} ; \mathrm{C}: \mathrm{Pm} 3 m$. For comparison, the results for a coarse-grain ceramic with $\mathrm{GS}=1.5 \mu \mathrm{m}$ are also listed.
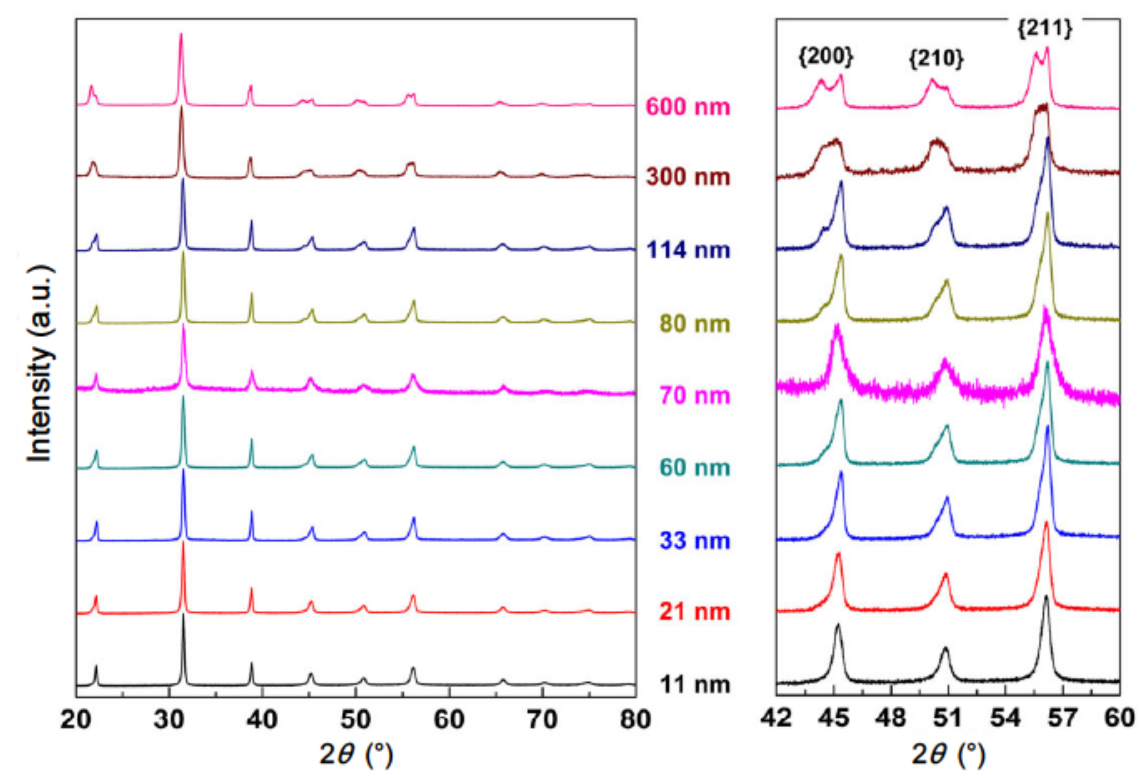

Fig. 20 XRD patterns of BSPT ceramics with different grain sizes. 
confirmed the existence of the tetragonal phase, and very likely it coexists with the monoclinic phase. This is similar to the case of $\mathrm{Pb}\left(\mathrm{Zr}, \mathrm{Ti} \mathrm{O}_{3}\right.$ (PZT) and $\mathrm{Pb}(\mathrm{Mg}, \mathrm{Nb}) \mathrm{O}_{3}-\mathrm{PbTiO}_{3}$ (PMN-PT), two well-known ferroelectric ceramics near their respective morphotropic phase boundaries, which also comprise $\mathrm{T}$ and $M$ phases [92]. The structure parameters of the coarse-grain ceramics $(\mathrm{GS}=1.5 \mu \mathrm{m})$ were also refined and are presented in Table 6, which are consistent with the literature values $[93,94]$. Comparing these results, it is seen that the tetragonal distortion $(c / a-1)$ of BSPT is significantly reduced in nanograin ceramics.

Figure 21 shows the temperature dependence of the phase fraction of BSPT ceramics with different grain size according to the synchrotron XRD. At GS $<33 \mathrm{~nm}$, the $\mathrm{T}, \mathrm{M}$ and $\mathrm{C}$ phases coexist throughout the range of temperature studied $\left(25-500{ }^{\circ} \mathrm{C}\right)$. In particular, the ferroelectric $\mathrm{T}$ phase persists at $500{ }^{\circ} \mathrm{C}$, above the Curie temperature $450{ }^{\circ} \mathrm{C}$, in both $11 \mathrm{~nm}$ and $21 \mathrm{~nm}$ ceramics. In contrast, when $\mathrm{GS}=114 \mathrm{~nm}, \mathrm{~T}$ and $\mathrm{M}$ phases disappear at $450{ }^{\circ} \mathrm{C}$, giving way to the cubic phase at higher temperatures.
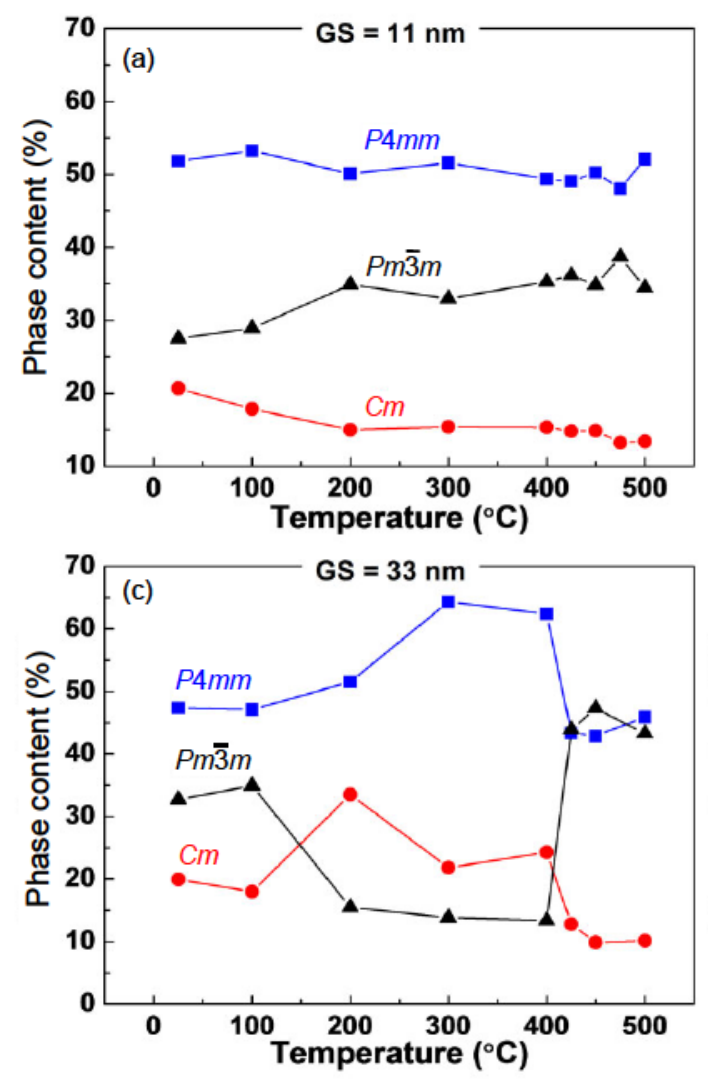

\section{2 Size effect on ceramic properties}

\section{2.1 Dielectric properties}

Dielectric properties of BSPT ceramics have not been widely reported especially regarding their grain size dependence in the nanoscale. Figure 22 shows the temperature spectra of dielectric constant and loss at $100 \mathrm{kHz}$ of BSPT ceramics with MPB composition at grain size ranging from $11 \mathrm{~nm}$ to $1.5 \mu \mathrm{m}$. The dielectric anomaly associated with the ferroelectric transition is clearly observed in all the samples, but it is also severely flattened and broadened at smaller grain size despite the fact that the Curie temperature remains almost unchanged, at $T_{\mathrm{C}} \approx 437{ }^{\circ} \mathrm{C}$.

\subsection{Ferroelectric properties}

Polarization-electric field $(P-E)$ hysteresis loops of coarse-grain $(0.5 \mu \mathrm{m}$ and $1.5 \mu \mathrm{m})$ BSPT ceramics (at the MPB composition) have a classic shape of square loops that are nearly saturated at large fields (Fig. 23(a)). When the grain size reduces to less than $100 \mathrm{~nm}$, however, polarization loops become much narrower and rounded indicating suppression of
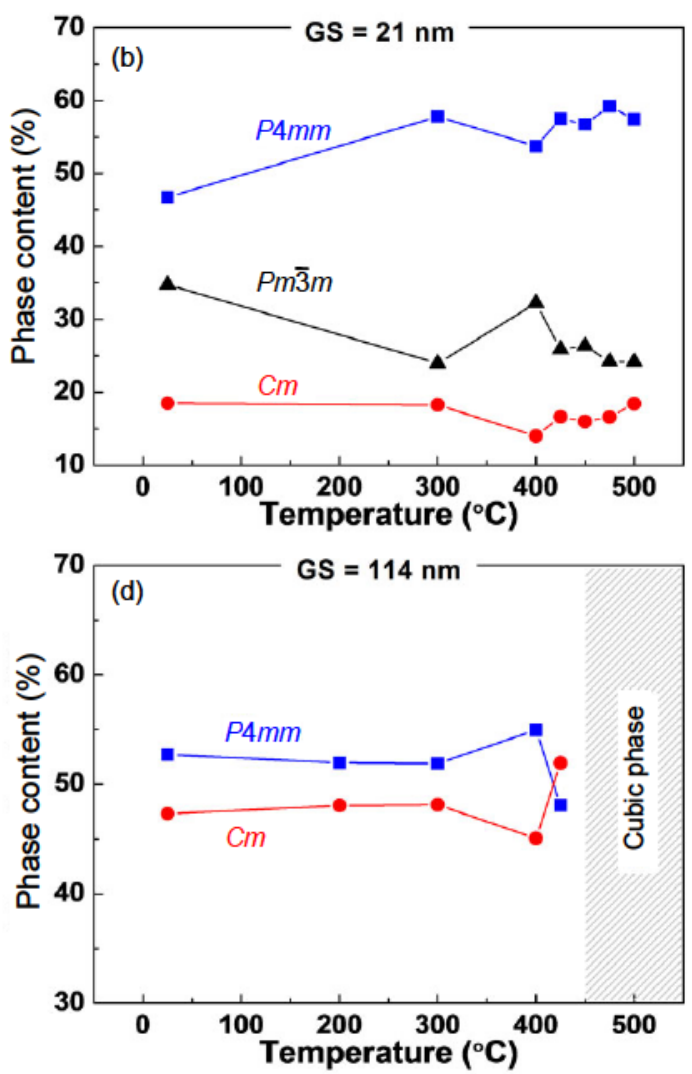

Fig. 21 Phase fraction of BSPT ceramics with different grain sizes. 
polarization switching. Similar results were observed in BSPT ceramics of a comparable composition prepared by SPS, reported by Amorín et al. [60], as shown in Fig. 23(b). Although polarization saturation is evident in Fig. 23(b) at large fields showing a monotonically decreasing saturation polarization as grain size decreases to $28 \mathrm{~nm}$, no saturation is apparent even at $60 \mathrm{kV} / \mathrm{cm}$ in finer-grain ceramics (e.g.,
$\mathrm{GS}=11 \mathrm{~nm}$ ) according to our data (Fig. 23(c)). This sequence of progressive clamping of polarization switching is also apparent in Fig. 23(d) for the same ceramic but at $\mathrm{GS}=114 \mathrm{~nm}$, which shows some evidence of polarization saturation albeit at a relatively small polarization. Such clamping may be attributed to the increasing fraction of dielectrically inactive (nonpolar) grain boundaries in nanograin ceramics.

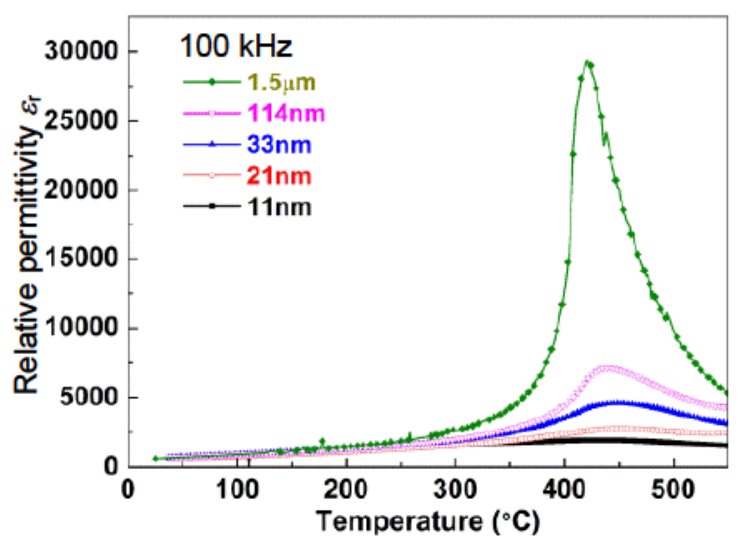

(a)

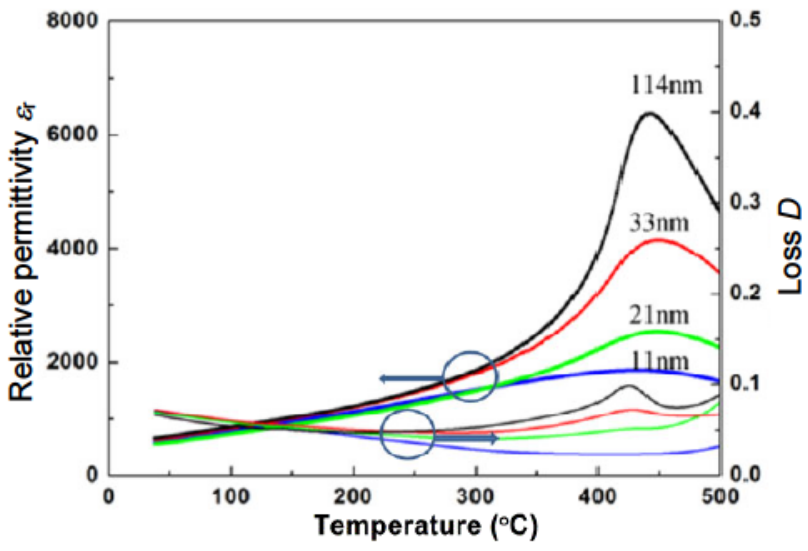

(b)

Fig. 22 Grain size effect on dielectric properties of BSPT ceramics: (a) temperature spectra of dielectric constant with grain size ranging from nanometer to micrometer; (b) the same as (a) for nanograin ceramics, along with their dielectric loss.
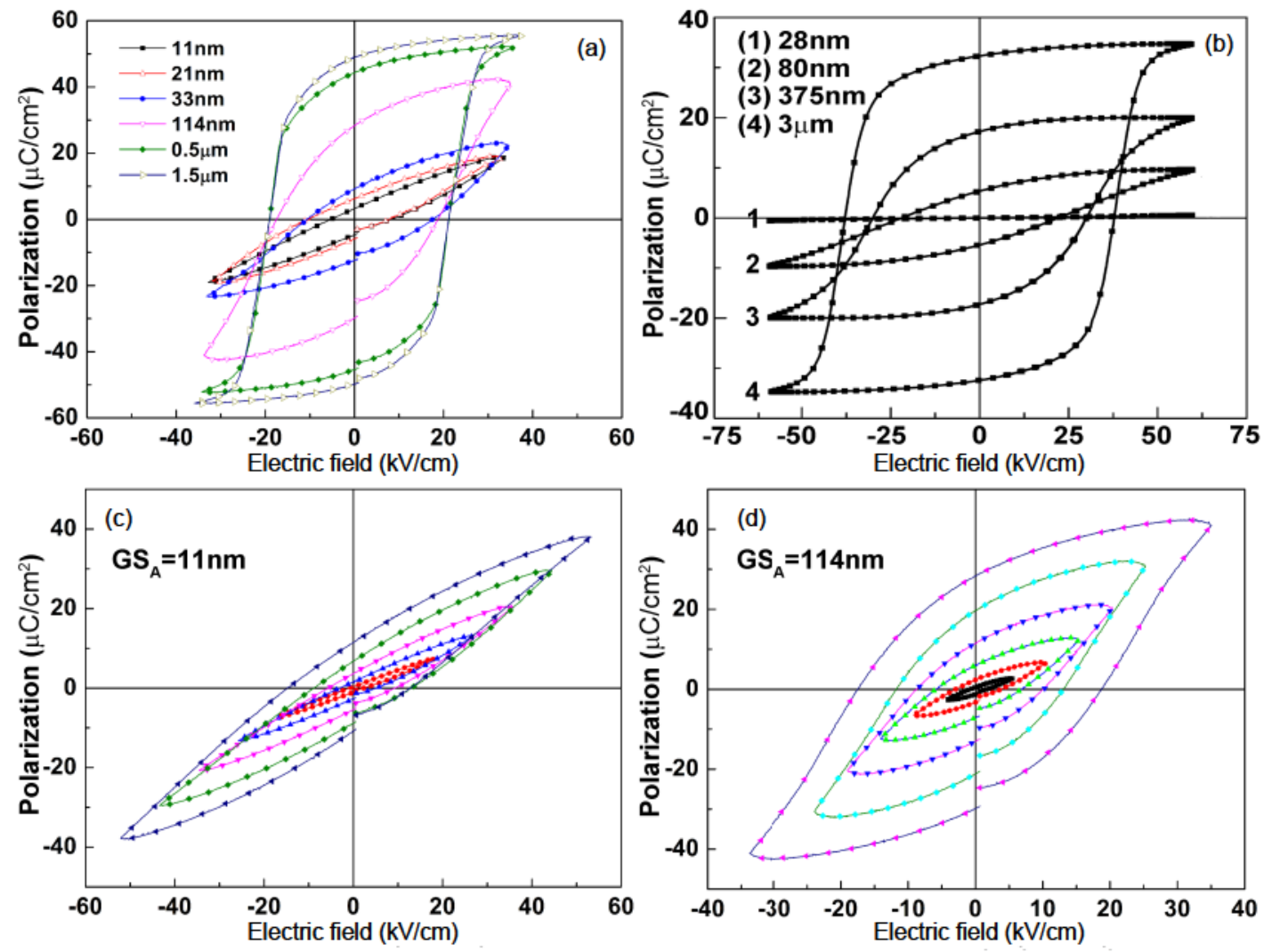

Fig. 23 (a) Grain size effect on the hysteresis loops of BSPT ceramics obtained by two-step sintering method; (b) the same as (a) according to Ref. [60]; (c) and (d) hysteresis loops at increasing fields of BSPT ceramics with GS=11 nm and $114 \mathrm{~nm}$, respectively. 
Since the applied voltage is mostly spent in the nonpolar region, the effective field available for polarization switching in the polar region is greatly reduced; i.e., it may be explained by the "dead layer" effect. (The interpretation in the literature [60] in terms of "exceptionally high resistivity" of the grain boundaries with the smallest grain size, thus resulting in screening of the "electric field within the grains" is obviously incorrect for a set of capacitors.) In addition, the domain walls are likely to be pinned by grain boundaries and defects, thus "frozen" at finer grain size [13]. Therefore, bulk polarization switching is difficult in nanograin ceramics even though local switching under a much higher field is still possible.

\section{2.3 Piezoelectric properties}

The piezoelectric coefficient $\left(d_{33}\right)$ of MPB BSPT ceramics obtained by TSS also manifests a peak $(700 \mathrm{pC} / \mathrm{N})$ at an intermediate grain size around $1.5 \mu \mathrm{m}$ as shown in Fig. 24 [25]. This value is much higher than that of coarse-grain BSPT ceramics $(450 \mathrm{pC} / \mathrm{N})$ prepared by conventional sintering methods. Importantly, over a relatively wide range of sub-micrometer grain size of $200-1000 \mathrm{~nm}, d_{33}$ can maintain a very high value (above $520 \mathrm{pC} / \mathrm{N}$ ), which seems to suggest that nanosized domains may contribute to enhanced piezoelectricity [87-89]. Piezoresponse force micrographs of these ceramics did reveal a fine domain structure probably composed of $90^{\circ}$ domains of $60-70 \mathrm{~nm}$ in width [25]. Therefore, their superior piezoelectric properties could be a result of both the MPB composition $(x=0.635)$ and the small domain size. However, when the grain size further reduces to the nano-scale (less than $100 \mathrm{~nm}$ ), the piezoelectricity once again decreases rapidly just like the dielectric constant, indicating the same physical mechanism that causes clamping of ferroelectricity in

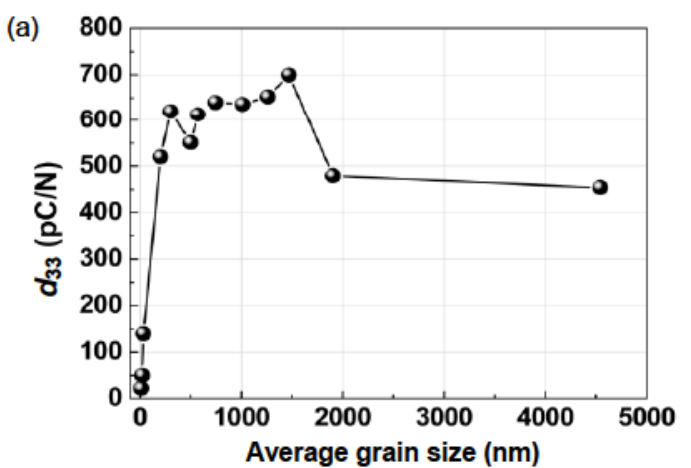

bulk nanograin ceramics is at play here as well. This is the case at least under the electric field strength $(40 \mathrm{kV} / \mathrm{cm})$ used in this study.

Local piezoresponse measurements of BSPT ceramics similar to those of BT ceramics were carried out by scanning probe microscopy (SPM) with a conductive $\mathrm{Rh}$ coated $\mathrm{Si}$ cantilever (bias voltage $V$ from $-100 \mathrm{~V}$ to $100 \mathrm{~V}$ over a small AC excitation of $5 \mathrm{kHz}$ ). Typical butterfly-shaped displacement-voltage $(Z-V)$ loops from such measurements are shown in Fig. 25 (blue curves). The effective piezoelectric coefficient $d_{33}^{*}$ can be estimated from the slope of the curve, exhibiting piezoelectric hysteresis (red curves in Fig. 25). Such measurements confirmed that BSPT nanoceramics $(\mathrm{GS}=11 \mathrm{~nm})$ is ferroelectric under a high local field [91]. The effective local piezoelectric coefficient $d_{33}^{*}$ was $292.9 \pm 29.8 \mathrm{pm} / \mathrm{V}$, smaller than that of coarse-grain BSPT ceramics but much larger than the macroscopic $d_{33}$ in Fig. 24. The latter difference is due to the very different electric fields in the two experiments: the SPM electric field is very high but confined in a small region of a dimension commensurate with the tip radius of the cantilever tip, wherein substantial switching of nanodomains and a strong piezoelectric response are possible; such high field cannot be reached in bulk ceramics because of dielectric breakdown.

\section{Summary and outlook}

Highly dense undoped $\mathrm{BaTiO}_{3}$ and $(\mathrm{Bi}, \mathrm{Pb})(\mathrm{Sc}, \mathrm{Ti}) \mathrm{O}_{3}$ ceramics with average grain size from several micrometers down to $5-10 \mathrm{~nm}$ have been successfully prepared by the two-step sintering method, some with additional modifications to aid densification. A pronounced and ubiquitous size effect on the

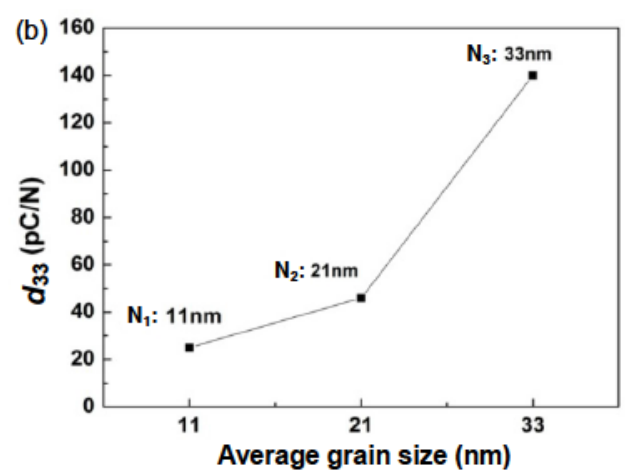

Fig. 24 Grain size effect on macroscopic piezoelectric properties of BSPT ceramics: (a) from micro to nano scale; (b) nano-scale. 

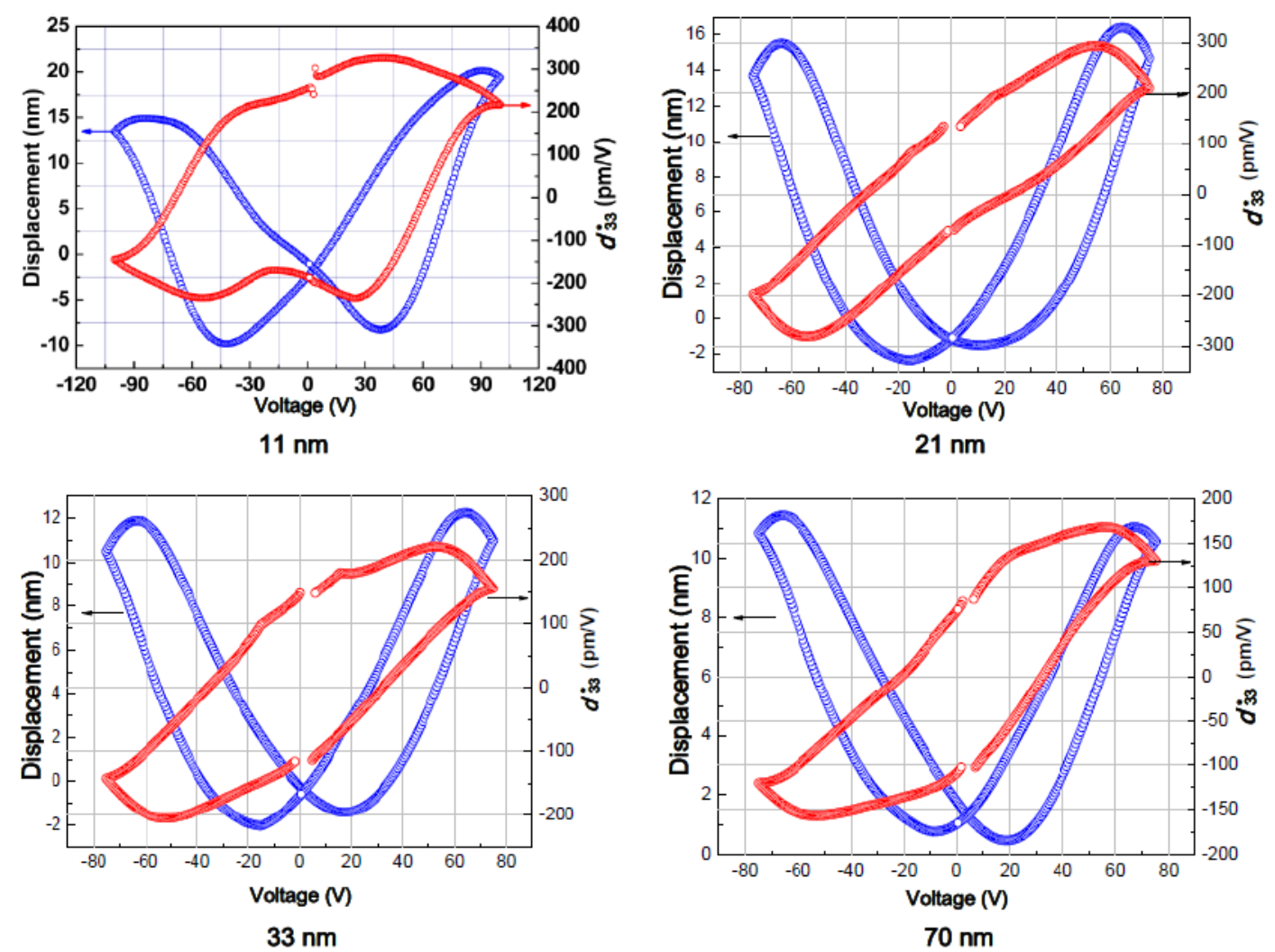

Fig. 25 Local piezoelectric response versus applied voltage of BSPT nanoceramics of four grain sizes.

microstructure and ferroelectric properties (including piezoelectric properties and dielectric anomaly) occurring at $\mathrm{GS} \approx 1 \mu \mathrm{m}$ and smaller has been established based on the evidence of XRD, HRTEM, AFM, SPM, dielectric constant $(K)$, piezoelectric coefficient $\left(d_{33}\right)$ and $P-E$ or displacement-voltage hysteresis. Although ferroelectricity and domain switching are substantially suppressed in nanograin ceramics in bulk samples, a strong local field such as that present under the conducting tip of an atomic force microscope or piezoresponse force microscope can induce local domain switching manifesting robust ferroelectricity and piezoelectricity even at a grain size of $5-10 \mathrm{~nm}$. Meanwhile, a flattened but somewhat extended dielectric and piezoelectric anomaly maintaining high responsivity values $\left(K, d_{33}\right)$ relatively close to their peak values is also seen at sub-1000 nm grain size. Importantly, this enables nanograin ceramics to exhibit a higher figure of merit at $25{ }^{\circ} \mathrm{C}$ than the state-of-the-art MLCC ceramics featuring $\mathrm{GS}=100 \mathrm{~nm}$. Moreover, the confirmation of ferroelectricity at $\mathrm{GS}=5-10 \mathrm{~nm}$ avails the possibility of unlocking versatile ferroelectricity-enabled properties provided ingenious means to relieve grain-size-related internal stresses/fields can be constructed. In this way, the fundamental studies reviewed here, made possible by nanograin ceramics obtained by two-step sintering, have provided the essential insight and a most valuable outlook to guide current and future MLCC technology as well as the further development of advanced ferroelectric and piezoelectric devices.

\section{Acknowledgements}

We thank Wojciech Dmowski (Joint Institute for Neutron Sciences, Oak Ridge National Laboratory, PO Box 2008, Oak Ridge, TN 37831-6453, USA, wdmowski@utk.edu) for synchrotron XRD measurements. The work was supported by Ministry of Sciences and Technology of China through National Basic Research Program of China (973 Program No. 2009CB623301), National Natural Science Foundation of China for Creative Research Groups (Grant No. 51221291). IWC and YDW's research was supported by the US National Science Foundation (Grant Nos. DMR0907523 and DMR1409114). They also acknowledge the use of facilities supported by the US National Science Foundation (Grant No. DMR1120901). We would like to thank Dr. TieYu Sun, 
ShaoPeng Zhang and Hui Zhang for their contributions for this work.

Open Access: This article is distributed under the terms of the Creative Commons Attribution License which permits any use, distribution, and reproduction in any medium, provided the original author(s) and the source are credited.

\section{References}

[1] Cross LE. Dielectric, piezoelectric and ferroelectric components. Am Ceram Soc Bull 1984, 63: 586-590.

[2] Hennings D, Klee M, Waser R. Advanced dielectrics: Bulk ceramics and thin films. Adv Mater 1991, 3: 334-340.

[3] Suzuki K, Kageyama K, Takagi H, et al. Fabrication of monodispersed barium titanate nanoparticles with narrow size distribution. J Am Ceram Soc 2008, 91: 1721-1724.

[4] Yoon S, Baik S. Formation mechanisms of tetragonal barium titanate nanoparticles in alkoxide-hydroxide sol-precipitation synthesis. J Am Ceram Soc 2006, 89: 1816-1821.

[5] Kishi H, Mizuno Y, Chazono H. Base-metal electrode-multilayer ceramic capacitors: Past, present and future perspectives. Jpn J Appl Phys 2003, 42: 1-15.

[6] Sakabe Y, Reynolds T. Base-metal electrode capacitors. Am Ceram Soc Bull 2002, 81: 24-26.

[7] Tian ZB, Wang XH, Lee S, et al. Microstructure evolution and dielectric properties of ultrafine grained $\mathrm{BaTiO}_{3}$-based ceramics by two-step sintering. J Am Ceram Soc 2011, 94 : 1119-1124.

[8] Uchino K, Sadanaga E, Hirose T. Dependence of the crystal structure on particle size in barium titanate. $\mathrm{J} \mathrm{Am}$ Ceram Soc 1989, 72: 1555-1558.

[9] Frey MH, Payne DA. Grain size effect on structure and phase transformations for barium titanate. Phys Rev B 1996, 54: $3158-3168$.

[10] Saad MM, Baxter P, Bowman RM, et al. Intrinsic dielectric response in ferroelectric nano-capacitors. J Phys: Condens Matter 2004, 16: L451-L456.

[11] Ishidate $\mathrm{T}$, Abe $\mathrm{S}$, Takahashi $\mathrm{H}$, et al. Phase diagram of $\mathrm{BaTiO}_{3}$. Phys Rev Lett 1997, 78: 2397-2400.

[12] Zhao Z, Buscaglia V, Viviani M, et al. Grain-size effects on the ferroelectric behavior of dense nanocrystalline $\mathrm{BaTiO}_{3}$ ceramics. Phys Rev B 2004, 70: 024107.

[13] Buscaglia V, Buscaglia MT, Viviani M, et al. Raman and AFM piezoresponse study of dense $\mathrm{BaTiO}_{3}$ nanocrystalline ceramics. J Eur Ceram Soc 2005, 25: 3059-3062.

[14] Polotai AV, Ragulya AV, Randall CA. The XRD and IR study of the barium titanate nano-powder obtained via oxalate route. Ferroelectrics 2004, 298: 243-251.

[15] Buscaglia MT, Viviani M, Buscaglia V, et al. High dielectric constant and frozen macroscopic polarization in dense nanocrystalline $\mathrm{BaTiO}_{3}$ ceramics. Phys Rev B 2006, 73: 064114.

[16] Wang XH, Deng XY, Wen $\mathrm{H}$, et al. Phase transition and high dielectric constant of bulk dense nanograin barium titanate ceramics. Appl Phys Lett 2006, 89: 1-3.

[17] Sun TY, Wang $\mathrm{XH}$, Wang $\mathrm{H}$, et al. A phenomenological model on phase transitions in nanocrystalline barium titanate ceramic. J Am Ceram Soc 2010, 93: 2571-2573.

[18] Zhang H, Wang XH, Tian ZB, et al. Fabrication of monodispersed 5-nm $\mathrm{BaTiO}_{3}$ nanocrystals with narrow size distribution via one-step solvothermal route. $\mathrm{J} \mathrm{Am}$ Ceram Soc 2011, 94: 3220-3222.

[19] Eitel RE, Randall CA, Shrout TR, et al. New high temperature morphotropic phase boundary piezoelectrics based on $\mathrm{Bi}(\mathrm{Me}) \mathrm{O}_{3}-\mathrm{PbTiO}_{3}$ ceramics. Jph J Appl Phys 2001, 40: 5999-6002.

[20] Goldschmidt V. Skrifter Norske Videnskaps-Akademi. Oslo, Matemot-Natureid Klasse 1926, 1: 7.

[21] Tutuncu G, Damjanovic D, Chen J, et al. Deaging and asymmetric energy landscapes in electrically biased ferroelectrics. Phys Rev Lett 2012, 108: 177601.

[22] Gotmare SW, Leontsev SO, Eitel RE. Thermal degradation and aging of high-temperature piezoelectric ceramics. $J \mathrm{Am}$ Ceram Soc 2010, 93: 1965-1969.

[23] Sehirlioglu A, Sayir A, Dynys F. High temperature properties of $\mathrm{BiScO}_{3}-\mathrm{PbTiO}_{3}$ piezoelectric ceramics. J Appl Phys 2009, 106: 014102.

[24] Zou TT, Wang XH, Zhao W, et al. Preparation and properties of fine-grain $(1-x) \mathrm{BiScO}_{3}-x \mathrm{PbTiO}_{3}$ ceramics by two-step sintering. J Am Ceram Soc 2008, 91: 121-126.

[25] Zou TT, Wang XH, Wang $\mathrm{H}$, et al. Bulk dense fine-grain $(1-x) \mathrm{BiScO}_{3}-x \mathrm{PbTiO}_{3}$ ceramics with high piezoelectric coefficient. Appl Phys Lett 2008, 93: 192913.

[26] Grinberg I, Rappe AM. Nonmonotonic $T_{\mathrm{C}}$ trends in Bi-based ferroelectric perovskite solid solutions. Phys Rev Lett 2007, 98: 037603.

[27] Chaigneau J, Kiat JM, Malibert C, et al. Morphotropic phase boundaries in $\left(\mathrm{BiScO}_{3}\right)_{(1-x)}\left(\mathrm{PbTiO}_{3}\right)_{x}(0.60<x<0.75)$ and their relation to chemical composition and polar order. Phys Rev B 2007, 76: 094111.

[28] Chen S, Dong XL, Mao CL, et al. Thermal stability of $(1-x) \mathrm{BiScO}_{3}-x \mathrm{PbTiO}_{3}$ piezoelectric ceramics for high-temperature sensor applications. J Am Ceram Soc 2006, 89: 3270-3272.

[29] Inaguma Y, Miyaguchi A, Yoshida M, et al. High-pressure synthesis and ferroelectric properties in perovskite-type $\mathrm{BiScO}_{3}-\mathrm{PbTiO}_{3}$ solid solution. J Appl Phys 2004, 95: 231-235.

[30] Randall CA, Eitel RE, Shrout TR, et al. Transmission electron microscopy investigation of the high temperature $\mathrm{BiScO}_{3}-\mathrm{PbTiO}_{3}$ piezoelectric ceramic system. J Appl Phys 2003, 93: 9271-9274.

[31] Eitel RE, Randall CA, Shrout TR, et al. Preparation and characterization of high temperature perovskite ferroelectrics in the solid-solution $(1-x) \mathrm{BiScO}_{3}-x \mathrm{PbTiO}_{3}$. Jpn J Appl Phys 2002, 41: 2099-2104.

[32] Zhang SJ, Randall CA, Shrout TR. Dielectric and piezoelectric properties of $\mathrm{BiScO}_{3}-\mathrm{PbTiO}_{3}$ crystals with morphotropic phase boundary composition. Jpn J Appl Phys 2004, 43: 6199-6203.

[33] Zhang SJ, Randall CA, Shrout TR. Dielectric, piezoelectric 
and elastic properties of tetragonal $\mathrm{BiScO}_{3}-\mathrm{PbTiO}_{3}$ single crystal with single domain. Solid State Commun 2004, 131 : 41-45.

[34] Zhang SJ, Randall CA, Shrout TR. Electromechanical properties in rhombohedral $\mathrm{BiScO}_{3}-\mathrm{PbTiO}_{3}$ single crystals as a function of temperature. Jpn J Appl Phys 2003, 42: L1152-L1154.

[35] Zhang SJ, Randall CA, Shrout TR. High Curie temperature piezocrystals in the $\mathrm{BiScO}_{3}-\mathrm{PbTiO}_{3}$ perovskite system. Appl Phys Lett 2003, 83: 3150-3152.

[36] Zhang SJ, Lebrun L, Rhee S, et al. Crystal growth and characterization of new high Curie temperature $(1-x) \mathrm{BiScO}_{3}-x \mathrm{PbTiO}_{3}$ single crystals. J Cryst Growth 2002, 236: 210-216.

[37] Zhong CF, Wang XH, Fang JA, et al. Investigation of thickness dependence of structure and electric properties of sol-gel-derived $\mathrm{BiScO}_{3}-\mathrm{PbTiO}_{3}$ thin films. J Am Ceram Soc 2010, 93: 3305-3311.

[38] Zhong $\mathrm{CF}$, Wang $\mathrm{XH}$, Wen $\mathrm{H}$, et al. Fabrication and properties of epitaxial growth $\mathrm{BiScO}_{3}-\mathrm{PbTiO}_{3}$ thin film via a hydrothermal method. Appl Phys Lett 2008, 92: 222910.

[39] Wen H, Wang XH, Zhong CF, et al. Epitaxial growth of sol-gel derived $\mathrm{BiScO}_{3}-\mathrm{PbTiO}_{3}$ thin film on $\mathrm{Nb}$-doped $\mathrm{SrTiO}_{3}$ single crystal substrate. Appl Phys Lett 2007, 90: 202902.

[40] Wen $\mathrm{H}$, Wang $\mathrm{XH}$, Zhong $\mathrm{CF}$, et al. Properties of compositionally graded $\mathrm{BiScO}_{3}-\mathrm{PbTiO}_{3}$ thin films fabricated by a sol-gel process. J Am Ceram Soc 2007, 90: 2441-2445.

[41] Wen $\mathrm{H}$, Wang $\mathrm{XH}, \mathrm{Li}$ LT. Orientation control in sol-gel-derived $\mathrm{BiScO}_{3}-\mathrm{PbTiO}_{3}$ thin films. $\mathrm{J} \mathrm{Am} \mathrm{Ceram}$ Soc 2007, 90: 3248-3254.

[42] Wen H, Wang XH, Deng XY, et al. Effect of crystallization process on the ferroelectric properties of sol-gel derived $\mathrm{BiScO}_{3}-\mathrm{PbTiO}_{3}$ thin films. $J$ Appl Phys 2007, 101: 016103.

[43] Yoshimura T, Trolier-McKinstry S. Growth and properties of (001) $\mathrm{BiScO}_{3}-\mathrm{PbTiO}_{3}$ epitaxial films. Appl Phys Lett 2002, 81: 2065-2066.

[44] Scott JF. Applications of modern ferroelectrics. Science 2007, 315: 954-959.

[45] Mao YB, Banerjee S, Wong SS. Hydrothermal synthesis of perovskite nanotubes. Chem Commun 2003, 3: 408-409.

[46] Boulosa M, Guillemet-Fritsch S, Mathieu F, et al. Hydrothermal synthesis of nanosized $\mathrm{BaTiO}_{3}$ powders and dielectric properties of corresponding ceramics. Solid State Ionics 2005, 176: 1301-1309.

[47] Chen IW, Wang XH. Sintering dense nanocrystalline ceramics without final-stage grain growth. Nature 2000, 404: 168-171.

[48] Wang DL, Zhu KJ, Ji HL, et al. Two-step sintering of the pure $\mathrm{K}_{0.5} \mathrm{Na}_{0.5} \mathrm{NbO}_{3}$ lead-free piezoceramics and its piezoelectric properties. Ferroelectrics 2009, 392: $120-126$.

[49] Mazaheri M, Zahedi AM, Haghighatzadeh M, et al. Sintering of titania nanoceramic: Densification and grain growth. Ceram Int 2009, 35: 685-691.

[50] Maca K, Pouchly V, Zalud P. Two-step sintering of oxide ceramics with various crystal structures. $J$ Eur Ceram Soc 2010, 30: 583-589.

[51] Wang XH, Deng XY, Bai HL, et al. Two-step sintering of ceramics with constant grain-size, II: $\mathrm{BaTiO}_{3}$ and $\mathrm{Ni}-\mathrm{Cu}-\mathrm{Zn}$ ferrite. J Am Ceram Soc 2006, 89: 438-443.

[52] Wang $\mathrm{XH}$, Chen IW. Sintering of nanoceramics. In Nanomaterials Handbook. Gogotsi Y, Ed. New York: Taylor Francis, 2006: 359-382.

[53] Kim HD, Han BD, Park DS, et al. Novel two-step sintering process to obtain a bimodal microstructure in silicon nitride. J Am Ceram Soc 2002, 85: 245-252.

[54] Wang XH, Chen PL, Chen IW. Two-step sintering of ceramics with constant grain-size, $\mathrm{I} . \mathrm{Y}_{2} \mathrm{O}_{3} . J$ Am Ceram Soc 2006, 89: 431-437.

[55] Wang XH, Deng XY, Zhou $\mathrm{H}$, et al. Bulk dense nanocrystalline $\mathrm{BaTiO}_{3}$ ceramics prepared by novel pressureless two-step sintering method. $J$ Electroceram 2008, 21: 230-233.

[56] Li LT, Wang XH, Zhang H, et al. Size effect investigation on nano-scale ferroelectric ceramic materials. Proceeding of 8th International Conference and Tabletop Exhibition on Ceramic Interconnect and Ceramic Microsystems Technologies (CICMT 2012) Erfurt, Germany, April 16-19, 2012: 000216-000221.

[57] Huan Y, Wang XH, Fang J, et al. Grain size effects on piezoelectric properties and domain structure of $\mathrm{BaTiO}_{3}$ ceramics prepared by two-step sintering. J Am Ceram Soc 2013, 96: 3369-3371.

[58] Huan Y, Wang XH, Fang J, et al. Grain size effect on piezoelectric and ferroelectric properties of $\mathrm{BaTiO}_{3}$ ceramics. J Eur Ceram Soc 2014, 34: 1445-1448.

[59] Algueró M, Amorín H, Hungría $\mathrm{T}$, et al. Macroscopic ferroelectricity and piezoelectricity in nanostructured $\mathrm{BiScO}_{3}-\mathrm{PbTiO}_{3}$ ceramics. Appl Phys Lett 2009, 94: 012902.

[60] Amorín H, Jiménez R, Ricote J, et al. Apparent vanishing of ferroelectricity in nanostructured $\mathrm{BiScO}_{3}-\mathrm{PbTiO}_{3}$. J Phys D: Appl Phys 2010, 43: 285401.

[61] Zhang SP, Wang XH, Wang $\mathrm{H}$, et al. Grain boundary region and local piezoelectric response of $\mathrm{BiScO}_{3}-\mathrm{PbTiO}_{3}$ nanoceramics prepared by combination of SPS and two-step sintering. J Eur Ceram Soc 2014, 34: 2317-2323

[62] Wang XH, Zhang SP, Li LT. Piezoelectric nanoceramics. In Springer Handbook of Nanomaterials. Vajtai R, Ed. Berlin Heidelberg: Springer, 2013: 553-570.

[63] Burns G, Scott BA. Raman studies of underdamped soft modes in $\mathrm{PbTiO}_{3}$. Phys Rev Lett 1970, 25: 167-169.

[64] Fu D, Suzuki H, Ishikawa K. Size-induced phase transition in $\mathrm{PbTiO}_{3}$ nanocrystals: Raman scattering study. Phys Rev B 2000, 62: 3125-3129.

[65] Pirc R, Blinc R. Off-center Ti model of barium titanate. Phys Rev B 2004, 70: 134107 .

[66] Keramidas VG, White WB. Raman scattering from $\mathrm{Ca}_{x} \mathrm{Zr}_{1-x} \mathrm{O}_{2-x} \square_{x}$, a system with massive point defects. J Phys Chem Solids 1973, 34: 1873-1878.

[67] Li P, Chen I-W, Penner-Hahn JE. X-ray absorption studies of zirconia polymorphs I. Characteristic local structures. Phys Rev B 1993, 48: 10063-10073. 
[68] Li P, Chen I-W, Penner-Hahn JE. X-ray absorption studies of zirconia polymorphs II. Effects of $\mathrm{Y}_{2} \mathrm{O}_{3}$ dopant on $\mathrm{ZrO}_{2}$ structure. Phys Rev B 1993, 48: 10074-10081.

[69] Li P, Chen I-W, Penner-Hahn JE. The effects of dopants on zirconia stabilization-An X-ray absorption study I. Trivalent dopants. J Am Ceram Soc 1994, 77: 118-128.

[70] Shirane G, Frazer BC, Minkiewicz VJ, et al. Soft optic modes in barium titanate. Phys Rev Lett 1967, 19: 234-238.

[71] DiDomenico M, Wemble SH, Porto SPS. Raman spectrum of single-domain $\mathrm{BaTiO}_{3}$. Phys Rev 1968, 174: 522-523.

[72] Zhu J, Han W, Wang $\mathrm{XH}$, et al. Phase coexistence evolution of nano $\mathrm{BaTiO}_{3}$ as function of particle sizes and temperatures. J Appl Phys 2012, 112: 064110.

[73] Larson AC, von Dreele RB. General structure analysis system (GSAS). Los Alamos National Laboratory Report LAUR, 2004: 86-748.

[74] Kwei GH, Lawson AC, Billinge SJ, et al. Structures of the ferroelectric phases of barium-titanate. $J$ Phys Chem 1993, 97: 2368-2377.

[75] Lin S, Lu TQ, Jin CQ, et al. Size effect on the dielectric properties of $\mathrm{BaTiO}_{3}$ nanoceramics in a modified Ginsburg-Landau-Devonshire thermodynamic theory. Phys Rev B 2006, 74: 134115.

[76] Buscaglia MT, Buscaglia V, Viviani M, et al. Ferroelectric properties of dense nanocrystalline $\mathrm{BaTiO}_{3}$ ceramics. Nanotechnology 2004, 15: 1113.

[77] Kinoshita K, Yamaji A, Grain-size effects on dielectric properties in barium-titanate ceramics. J Appl Phys 1976, 47: 371-373.

[78] Jaffe B, Cook WR, Jaffe H. Piezoelectric ceramics. London: Academic Press, 1971.

[79] Zheng $P$, Zhang J, Tan YQ, et al. Grain-size effects on dielectric and piezoelectric properties of poled $\mathrm{BaTiO}_{3}$ ceramics. Acta Mater 2012, 60: 5022-5030.

[80] Karaki T, Yan K, Adachi M. Barium titanate piezoelectric ceramics manufactured by two-step sintering. Jpn J Appl Phys 2007, 46: 7035-7038.

[81] Karaki T, Yan K, Adachi M. Subgrain microstructure in high-performance $\mathrm{BaTiO}_{3}$ piezoelectric ceramics. Appl Phys Express 2008, 1: 111402.

[82] Shao SF, Zhang JL, Zheng Z, et al. High piezoelectric properties and domain configuration in $\mathrm{BaTiO}_{3}$ ceramics obtained through the solid-state reaction route. $J$ Phys $D$ : Appl Phys 2008, 41: 125408.
[83] Takahashi H, Numamoto Y, Tani J, et al. Considerations for $\mathrm{BaTiO}_{3}$ ceramics with high piezoelectric properties fabricated by microwave sintering method. Jpn $J$ Appl Phys 2008, 47: 8468-8471.

[84] Ding SH, Song TX, Yang XJ, et al. Effect of grain size of $\mathrm{BaTiO}_{3}$ ceramics on dielectric properties. Ferroelectrics 2010, 402: 55-59.

[85] Arlt G, Hennings D, de With G. Dielectric properties of fine-grained barium titanate ceramics. J Appl Phys 1985, 58: $1619-1625$.

[86] Randall CA, Kim N, Kucera JP, et al. Intrinsic and extrinsic size effects in fine-grained morphotropic-phase-boundary lead zirconate titanate ceramics. J Am Ceram Soc 1998, 81: 677-688.

[87] Ahluwalia R, Lookman T, Saxena A, et al. Domain-size dependence of piezoelectric properties of ferroelectrics. Phys Rev B 2005, 72: 014112.

[88] Wada $\mathrm{S}$, Yako $\mathrm{K}$, Kakemoto $\mathrm{H}$, et al. Enhanced piezoelectric properties of barium titanate single crystals with different engineered-domain sizes. J Appl Phys 2005, 98: 014109 .

[89] Takahashi H, Numamoto Y, Tani J, et al. Lead-free barium titanate ceramics with large piezoelectric constant fabricated by microwave sintering. Jpn J Appl Phys 2006, 45: 7405 .

[90] Sato Y, Hirayama T, Ikuhara Y. Evolution of nanodomains under DC electrical bias in $\mathrm{Pb}\left(\mathrm{Mg}_{1 / 3} \mathrm{~N}_{\mathrm{b} 2 / 3}\right) \mathrm{O}_{3}-\mathrm{PbTiO}_{3}$ : An in-situ transmission electron microscopy study. Appl Phys Lett 2012, 100: 172902.

[91] Zhang SP, Wang XH, Zhu JL, et al. The microstructure and ferroelectricity of $\mathrm{BiScO}_{3}-\mathrm{PbTiO}_{3}$ nanoceramics at morphotropic phase boundaries. Scripta Mater 2014, 82: 45-48.

[92] Noheda B, Cox D, Shirane G, et al. Stability of the monoclinic phase in the ferroelectric perovskite $\mathrm{PbZr}_{1-x} \mathrm{Ti}_{x} \mathrm{O}_{3}$. Phys Rev B 2000, 63: 14103.

[93] Shahzad K, Li LH, Li ZR, et al. Structural characterization and dielectric properties of sol-gel synthesized $\mathrm{BiScO}_{3}-0.64 \mathrm{PbTiO}_{3}$ ceramics. Ferroelectrics 2010, 402: 142-149.

[94] Datta K, Walker D, Thomas PA. Structural investigations of the bismuth scandate-lead titanate $x \mathrm{BiScO}_{3}-(1-x) \mathrm{PbTiO}_{3}$ solid solution for $0.10 \leqslant x \leqslant 0.40$. Phys Rev B 2010, 82: 144108. 